\title{
Cenário Integrador: A Emergência de uma Proposta de Reconfiguração Curricular
}

\section{Integrator Scenario: The Emergence of a Curriculum Reconfiguration Proposal}

\author{
Sara Souza Pimenta \\ Thiago Santos Guimarães \\ Nataélia Alves da Silva \\ Andrei Steveen Moreno Rodríguez \\ Elisa Prestes Massena \\ Brasil \\ Brasil \\ Brasil \\ Brasil \\ Brasil
}

O currículo pode ser compreendido como uma das matrizes em que se personalizam formas variadas da produção social, no entanto, grande parte dos currículos escolares tem desfavorecido as classes sociais mais vulneráveis. Para superar isso, algumas propostas de reconfiguração curricular surgiram a fim de promover um ensino de Ciências contextualizado e intrínseco à realidade. É objetivo deste artigo, apresentar o processo de emergência e fundamentação da proposta de reconfiguração curricular Cenário Integrador construída no contexto do Grupo de Pesquisa em Currículo e Formação de Professores em Ensino em Ciências (GPeCFEC). Essa proposta integra conjuntos de elementos que possibilitam o estudo de temas, situações e problemas reais de relevância social. Assim realizou-se análise documental a partir de um levantamento bibliográfico de Trabalhos de Conclusão de Curso (TCC) e Dissertações desenvolvidas respectivamente no âmbito do curso de Licenciatura em Química e do Programa de Pós-Graduação em Educação em Ciências, ambos da Universidade Estadual de Santa Cruz (UESC). Os resultados desse estudo apontam que o Cenário Integrador confere ao trabalho pedagógico escolar uma perspectiva crítica e social para além da aprendizagem do conceito. Essa proposta também pode contribuir para a integração de espaços escolares, acadêmicos e sociais, além de incentivar a atuação diferenciada de futuros professores e a formação continuada de seus participantes.

Palavras-chave: Reconfiguração Curricular; Currículo crítico; Ensino de Ciências.

The curriculum can be understood as one of the matrixes in which varied forms of social production are personalized, however, a large part of school curricula has disfavored the social classes most vulnerable. To overcome this, some proposals for curricular reconfiguration emerged in order to promote contextualized and intrinsic of the Science Teaching. The objective of this article is to present the emergency process and the rationale for the proposal of curricular reconfiguration Integrator Scenario built in the 
context of the GPeCFEC. This proposal integrates sets of elements that enable the study of themes, situations and real problems of social relevance. Thus, a documental analysis was carried out based on a bibliographic survey of monografies and master's thesis developed respectively within the scope of the Degree in Chemistry and the Graduate Program in Science Education, both from the University. The results of this study show that the Integrator Scenario gives work pedagogical, critical and social perspective beyond the concept learning. This proposal can also contribute to the integration of school, academic and social spaces, in addition to encouraging the different performance of future teachers and the continuing education of their participants.

Keywords: Curriculum Reconfiguration; Critical curriculum; Science teaching.

\section{Introdução}

O avanço das teorias do currículo tem contribuído para responder fatores sobre o ensino e aprendizagem - principal preocupação da linha do currículo tradicional. Para além disso, sabendo que o currículo é a matriz em que se personalizam formas variadas da produção social, o seu estudo permite compreender como a cultura influencia nos processos de educação, de ensino e de aprendizagem limitando ou permitindo a ascensão dos indivíduos na sociedade, sendo essas questões aprofundadas nas linhas do currículo crítico e pós-crítico (Sacristán, 1998; Silva, 1995; 2001).

Diante das demandas sociais e com o avanço das teorias curriculares corroborando a mudança dos currículos escolares, diversas Propostas de Reconfiguração Curricular foram desenvolvidas a fim de superar o foco conteudista do currículo tradicional e promover um ensino de Ciências contextualizado e intrínseco à realidade. Entre elas é possível citar as propostas Ciência, Tecnologia e Sociedade (Ratcliffe, Grace, 2003), Ciência, Tecnologia, Sociedade e Ambiente (Pedretti \& Nazir, 2011), Abordagem Temática Freireana (Delizoicov et al., 2011) e Situação de Estudo (Maldaner, 2007). Essas propostas são diferentes sugestões de como o currículo em nível escolar pode ser organizado a partir de um tema científico, social ou da vivência dos estudantes, o que pode facilitar o ensino dos conteúdos.

No âmbito da Universidade Estadual de Santa Cruz (UESC), entre os anos de 2009 a 2010, a Situação de Estudo começou a ser desenvolvida no Programa Institucional de Bolsas de Iniciação à Docência (PIBID) de Química pelos primeiros integrantes, que mais tarde constituiriam o Grupo de Pesquisa em Currículo e Formação de Professores em Ensino em Ciências (GPeCFEC) ${ }^{1}$. Em 2012, esse grupo de pesquisa firmou parceria com o Grupo Interdepartamental de Pesquisa sobre Educação em Ciências da Universidade Regional do Noroeste do Estado do Rio Grande do Sul (Gípec-Unijuí) por meio do projeto de pesquisa aprovado em Edital CNPq Universal 14/2011 (Massena, Brito, 2015;

1 O GPeCFEC desenvolve processos de formação inicial e continuada de professores no âmbito do curso de Licenciatura em Química da UESC e em escolas da região Sul da Bahia. Maiores informações sobre os trabalhos e atividades do GPeCFEC podem ser encontradas no endereço https://gruposdepesquisa.wixsite.com/gpecfec. 
Sousa, 2018), que tinha como objetivo desenvolver e investigar a proposta Situação de Estudo.

A Situação de Estudo baseia-se em uma "situação concreta, da vivência dos alunos, rica conceitualmente para diversos campos da ciência, de forma a permitir a análise interdisciplinar e estabelecer interconexões transdisciplinares" (Maldaner, 2007, p. 248). Metodologicamente, essa proposta de reconfiguração curricular é planejada e desenvolvida por um coletivo docente, do qual fazem parte professores do Ensino Superior, professores da Educação Básica, licenciandos e pós-graduandos. Esse coletivo tem a função de "eleger os conceitos científicos mais representativos e o nível de significação dos mesmos, com a finalidade de propiciar uma compreensão mais plena da situação em foco" (Pansera-de-Araújo et al., 2007, p. 170). Para isso, são escolhidos temas amplos com base em temas transversais. Assim, segundo Maldaner (2007) os conceitos podem ser trabalhados por vertente transdisciplinar, transitando dentro da área de Ciências da Natureza, entre as disciplinas de Química, Física e Biologia.

Maldaner e Zanon (2006) indicavam que, ao passo que novas Situações de Estudo fossem produzidas, outros referenciais e diferentes formas de planejamento poderiam surgir. Nessa perspectiva, diversas propostas foram elaboradas no contexto do GPeCFEC. Inclusive Vieira (2017), Vieira et al. (2018) apontam uma produção significativa de trabalhos em Anais de eventos e artigos sobre essa proposta, provindos da região Nordeste.

A Situação de Estudo se preocupa principalmente com os fatores cognitivos da aprendizagem e, seu principal fator de reconfiguração está centrado em trabalhar o conceito científico de modo interdisciplinar. Com isso, tem-se percebido que as demandas sociais não são atendidas nessa proposta, o que tem dificultado a sua implementação. Assim, alguns pesquisadores e discentes que desenvolvem ou desenvolveram a proposta da Situação de Estudo relatam a necessidade de diversas adaptações realizadas a fim de implementar tal reconfiguração nas escolas da região Nordeste, de modo a considerar as particularidades das escolas e as modalidades de ensino em que se tem trabalhado.

Por exemplo, Pimenta (2016) desenvolveu uma proposta de reconfiguração curricular abordando as questões étnico-raciais a partir da temática de cabelos cacheados em um curso técnico em Biocombustíveis. A proposta de Silva (2017) fomenta o debate acerca da poluição da água do Rio Almada a partir de conteúdos de Ciências da Natureza, incentivando a construção do ser social dos estudantes participantes. Almeida (2017) discute a problemática do gerenciamento do lixo na zona rural no contexto de Educação do Campo. Silva (2019) desenvolveu sua proposta sobre o tema de soberania alimentar em um Centro Integrado de um Movimento dos Trabalhadores Rurais Sem Terra (MST).

Essa contínua produção de propostas curriculares, no contexto do GPeCFEC, passou a ser um ato de investigação das próprias ações, na tentativa de melhorá-las num movimento de pesquisa-ação (Tripp, 2005; Zubbert-Skerrtitt, 2005). E, quanto às características dessa proposta a respeito de seu desenvolvimento em escolas de uma 
região de contexto diferenciado como o Nordeste brasileiro, alguns questionamentos foram levantados como: "O que caracteriza essa proposta?", "Como e quem deve participar da construção da proposta?", "Quais são os critérios exigidos na escolha dos temas?".

Portanto, é objetivo deste artigo, apresentar o processo de emergência e fundamentação da proposta de reconfiguração curricular Cenário Integrador construída no contexto do GPeCFEC. Essa proposta integra conjuntos de elementos que possibilitam o estudo de temas, situações e problemas reais de relevância social.

\section{Reconfiguração curricular}

O currículo é uma seleção de cultura, pois sua estrutura, organização e o conhecimento ensinado na escola são escolhas de um grupo de pessoas. Isso significa que ele não é toda a cultura que existe, mas sim um resumo dela que pode servir à socialização e à reprodução, ainda que não objetive isso de modo prescrito. A cultura, portanto, se constrói e reconstrói segundo as condições particulares no processo de escolarização, de ensino e de aprendizagem podendo ser aprendida somente nos âmbitos práticos que constituem o sistema curricular (Sacristán, 1998).

Para Sacristán (2000, p. 101), o currículo deve ser compreendido como um sistema porque ele "cria em torno de si campos de ação diversos, nos quais múltiplos agentes e forças se expressam em sua configuração, incidindo sobre aspectos distintos." Isso significa que as atividades que permitem a funcionalidade do currículo só são possíveis quando pessoas e grupos de pessoas se apropriam e realizam tais atividades. $\mathrm{O}$ sistema curricular é, então, mantido em um processo não linear, dinâmico e fortemente relacionado aos fatores históricos.

Nesse sistema curricular, a criação, o gerenciamento e a manutenção das fases do currículo são realizados pelo contexto interno e o contexto externo. O contexto interno refere-se aos condicionamentos escolares, a aquilo que os agentes da escola selecionam e organizam para o currículo. Já o contexto externo influencia todos os contextos internos dos âmbitos práticos do currículo, estando intrínsecas nele as relações políticas, sociais econômicas, culturais e outros (Sacristán, 1998).

Sabendo que o contexto externo pode influenciar fortemente o currículo escolar, estabelece-se, por meio dele, uma via de mão dupla, pois, em outra direção, a sociedade pode ser dominada eficientemente por meio da educação e da cultura as quais irão atuar para a manutenção e exploração das relações hegemônicas vigentes no meio social (Apple, 1989).

Assim, controlar a vida cultural e seus decorrentes é controlar a prática cotidiana dos indivíduos, nisso se concentra o papel das instituições no sistema de nossa sociedade, das quais entre elas está a escola. $\mathrm{O}$ ato de ir à escola está entre as mais importantes práticas cotidianas em famílias de qualquer nível social, portanto, a educação é um dos meios mais massivos de dominação dos quais grupos dominantes podem se apropriar (Apple, 2006). Nesse sentido, a escola controla a vida cultural por meio do tipo e forma 
de conhecimento que ensina.

Embora o currículo seja um conjunto complexo de diversos elementos, podese entender que ele é configurado a partir de suas estruturas formais e funções sociais geridas por fatores sociais, políticos e econômicos. Acontece que as configurações que os currículos escolares têm tomado, tendem ainda a apresentar formas tradicionais que suscitam o conteudismo e o distanciamento entre a escola e a vida real dos estudantes. Sendo assim, considera-se que essa estrutura pode ser reconfigurada para alcançar um currículo que permita a transformação da realidade. Ou seja, por meio da construção de novas propostas de reconfiguração curricular.

Como a configuração do currículo por vezes ainda é compreendida como uma lista de conteúdos, então alguns se referem à Reconfiguração Curricular como "um processo caracterizado por variações na seleção dos conteúdos ensinados, com base na contextualização e na busca pela construção de sentidos para a aprendizagem." (Mesquita, 2019). Entretanto, variar o conteúdo é uma maneira simplista de mudar o currículo, isso seria somente uma reorganização em que a ordem dos conteúdos selecionados pela tradição seletiva (Apple, 2006) ocupa diferentes sequências, já que são os mesmos conteúdos trabalhados.

Outros associam esse termo "a produções cotidianas dos currículos escolares como lugar de reconfiguração dos currículos prescritos” (Campos, Reis, 2019). No entanto, as produções cotidianas das escolas só podem ser consideradas impulsoras de reconfiguração curricular se forem sistematizadas em nível de atividades correspondentes às práticas organizativas em estrutura e ordenação interna da escola (Sacristán, 1998).

Segundo o Magno Dicionário Brasileiro da Língua Portuguesa (Maia, 1995), a palavra configuração denota "forma de um corpo" ou "elementos culturais que se encontram em uma certa área, em um certo tempo", portanto entende-se Reconfiguração Curricular como o ato de configurar novamente o currículo atual de um país, escola ou disciplina, dando-lhe uma nova forma ou trazendo novos elementos culturais.

Nesse artigo, considera-se a reconfiguração curricular de acordo com os níveis do currículo definidos por Sacristán (1998, 2000), quais sejam: a) Currículo Organizado - o qual corresponde às práticas organizativas em uma estrutura e ordenação interna da escola que caracteriza seu projeto; b) Currículo em ação - aquele em que se efetiva a prática real. É nele que a ação pedagógica se concretiza criando sentido e interação entre saber e cultura. Este nível de currículo se efetiva no âmbito da sala de aula, pois nela são realizadas as tarefas de aprendizagem que podem adotar um enfoque psicológico e social; e c) Currículo Avaliado - que é a forma do currículo mais direto e imediato ao estudante e diferencia-se das demais fases por suas características avaliativas. Neste é prevista uma nova organização das disciplinas, das atividades e das tarefas em direção de uma atitude dos professores mais politicamente engajada.

Mas mudar o currículo não deve estar associado somente em nível estrutural, devese fazer um esforço para que influências ideológicas e hegemônicas sejam descobertas e 
modificadas ou ao menos questionadas para que o currículo da escola se mantenha em reconfiguração. Para isso, é necessário alterar o estado de neutralidade na educação e na escola, caracterizado pelo ato de os professores e profissionais da educação não tratarem de problemas relevantes para a sociedade e para os estudantes, o que ajuda a manter as relações hegemônicas sustentadas pelo senso comum (Apple, 2006).

Nesse sentido, Apple (2006, p. 45) orienta a expandir tal estudo para além dos muros da instituição de ensino e de seu currículo, centrados na teoria da justiça social, contribuindo "para o benefício daqueles que estão em situação de desvantagem". O motivo é que, se as ações educativas não alcançarem a vida cultural das pessoas, pouco ou nada adiantam as tentativas de mudanças no âmbito escolar e, aqueles sujeitos em desvantagem social ainda continuarão em desvantagem (Apple, 1989).

Assim, a proposta de reconfiguração curricular pode criar condições para que a instituição coloque em discussão questões de relevância social e científica bem como permitir a emergência de novos currículos sintonizados com as demandas da sociedade por meio do estudo de temas (Simonneaux, 2014).

\section{Pesquisas e ações}

A fim de apresentar o processo de emergência no qual se identificou a proposta de reconfiguração curricular Cenário Integrador, foi realizado um levantamento bibliográfico e análise documental de Trabalhos de Conclusão de Curso (TCC) e Dissertações desenvolvidas no âmbito da UESC.

Para que a análise documental fosse realizada, as dissertações foram encontradas na página do Programa de Pós-Graduação de Educação em Ciências da UESC, por meio da busca do termo "Situação de Estudo" no título ou no resumo do texto. À vista de que os TCCs gerados em cursos de graduação da UESC não são disponibilizados on-line, os licenciandos que produziram seus TCCs sobre Situação de Estudo foram contatados e lhes foi solicitado o texto.

Após a classificação dessas pesquisas, foi realizada a leitura e análise dos textos, com uma atenção maior às seções de metodologia, resultados e discussão, e considerações finais, pois nessas seções os autores descrevem com mais detalhes a pesquisa e expressam suas percepções e concepções sobre as propostas de reconfiguração desenvolvidas ou analisadas em suas pesquisas. Em seguida, realizou-se a análise interpretativa dos termos mais frequentes nos textos, como tríade, trabalho coletivo, temas amplos, vivência e conceito pedagógico, sendo esses termos, nesse artigo, reinterpretados sob a concepção dos autores das pesquisas identificados e baseados em argumentos respaldados nas teorias adotadas.

Conforme apontam Guba e Lincoln (1981 citado em Lüdke \& André, 1986), a análise documental compreende diversas vantagens como a estabilidade (referente tanto ao tempo, quanto às variadas releituras que podem ser feitas por diferentes pessoas) e a grande quantidade de informações que comporta. Além disso, os documentos são sempre criados em um determinado contexto, por isso, símbolos desse contexto estarão 
presentes na escrita dos mesmos. Sendo assim, optou-se por analisar as pesquisas desenvolvidas sob a condição de que os autores tenham sido participantes do GPeCFEC ou orientados por professores pesquisadores da UESC que investigam sobre a Situação de Estudo, a fim de caracterizar a proposta emergente nesse cenário.

Foram identificadas vinte e uma (21) pesquisas, sendo que nove (9) são dissertações e doze (12) são TCCs. Na Figura 1, essas pesquisas são apresentadas por meio de informações sobre o autor, título, caráter, ano de defesa da pesquisa e o objetivo correspondente a abordagem da proposta de reconfiguração que cada pesquisa adotou.

\begin{tabular}{|c|c|c|c|c|}
\hline Autor & Título & Caráter & $\begin{array}{l}\text { Ano de } \\
\text { defesa }\end{array}$ & Objetivo \\
\hline $\begin{array}{l}\text { Amaral, } \\
\text { G. }\end{array}$ & $\begin{array}{l}\text { Situação de Estudo: Uma nova abordagem } \\
\text { curricular no curso técnico em } \\
\text { Biotecnologia. }\end{array}$ & TCC & 2013 & $\begin{array}{l}\text { Elaboração e } \\
\text { implementação da } \\
\text { proposta }\end{array}$ \\
\hline $\begin{array}{l}\text { Fernandes } \\
\text { F. G. }\end{array}$ & $\begin{array}{l}\text { Contribuições da Situação de Estudo } \\
\text { à Formação Inicial de Professores de } \\
\text { Química da Universidade Estadual de } \\
\text { Santa Cruz }\end{array}$ & TCC & 2014 & $\begin{array}{l}\text { Elaboração de } \\
\text { uma proposta }\end{array}$ \\
\hline $\begin{array}{l}\text { Pinto, J. G. } \\
\text { R. }\end{array}$ & $\begin{array}{l}\text { Situação de Estudo: Automedicação, } \\
\text { um mal necessário? Uma abordagem } \\
\text { curricular em um curso Técnico }\end{array}$ & TCC & 2015 & $\begin{array}{l}\text { Elaboração e } \\
\text { implementação da } \\
\text { proposta }\end{array}$ \\
\hline $\begin{array}{l}\text { Bomfim, } \\
\text { R. C. }\end{array}$ & $\begin{array}{l}\text { Automedicação como tema de Situação de } \\
\text { Estudo para o Ensino de Química }\end{array}$ & TCC & 2016 & $\begin{array}{l}\text { Elaboração e } \\
\text { implementação da } \\
\text { proposta }\end{array}$ \\
\hline $\begin{array}{l}\text { Pimenta, } \\
\text { S. S. }\end{array}$ & $\begin{array}{l}\text { Conhecendo a Química dos cabelos } \\
\text { cacheados: Uma situação de estudo no } \\
\text { curso técnico }\end{array}$ & TCC & 2016 & $\begin{array}{l}\text { Elaboração e } \\
\text { implementação da } \\
\text { proposta }\end{array}$ \\
\hline $\begin{array}{l}\text { Reis, C. M. } \\
\text { R. }\end{array}$ & $\begin{array}{l}\text { Educação de Jovens e Adultos: A Situação } \\
\text { de Estudo como possibilidade de repensar } \\
\text { o currículo }\end{array}$ & TCC & 2016 & $\begin{array}{l}\text { Elaboração e } \\
\text { implementação da } \\
\text { proposta }\end{array}$ \\
\hline $\begin{array}{l}\text { Santos, C. } \\
\text { E. J }\end{array}$ & $\begin{array}{l}\text { Possíveis contribuições da proposta } \\
\text { curricular Situação de Estudo no currículo } \\
\text { da Educação de Jovens e Adultos }\end{array}$ & TCC & 2016 & $\begin{array}{l}\text { Análise de } \\
\text { currículo }\end{array}$ \\
\hline $\begin{array}{l}\text { Guimarães, } \\
\text { T. S. }\end{array}$ & $\begin{array}{l}\text { O uso da literatura de Jorge Amado no } \\
\text { ensino de ciências: Uma possibilidade a } \\
\text { partir de uma Situação de Estudo }\end{array}$ & TCC & 2017 & $\begin{array}{l}\text { Elaboração e } \\
\text { implementação da } \\
\text { proposta }\end{array}$ \\
\hline $\begin{array}{l}\text { Sampaio, } \\
\text { T. S. }\end{array}$ & $\begin{array}{l}\text { Educação de Jovens e Adultos: Atividade } \\
\text { de formação continuada baseado nos } \\
\text { pressupostos da Situação de Estudo }\end{array}$ & TCC & 2017 & $\begin{array}{l}\text { Curso de } \\
\text { Formação }\end{array}$ \\
\hline $\begin{array}{l}\text { Silva, U. } \\
\text { K. }\end{array}$ & $\begin{array}{l}\text { RIO ALMADA: uma Situação de Estudo } \\
\text { como proposta para o ensino de Ciências }\end{array}$ & TCC & 2017 & $\begin{array}{l}\text { Elaboração e } \\
\text { implementação da } \\
\text { proposta }\end{array}$ \\
\hline $\begin{array}{l}\text { Pereira, D. } \\
\text { B. }\end{array}$ & $\begin{array}{l}\text { Alimento e gastrite: Possíveis } \\
\text { contribuições da Situação de Estudo para } \\
\text { o PROEJA }\end{array}$ & TCC & 2017 & $\begin{array}{l}\text { Análise de } \\
\text { currículo }\end{array}$ \\
\hline
\end{tabular}

Figura 1. Dissertações e TCCs desenvolvidos no contexto do Grupo de Pesquisa em Currículo e Formação de Professores em Ensino em Ciências (GPeCFEC) (continua) 


\begin{tabular}{|c|c|c|c|c|}
\hline Autor & Título & Caráter & $\begin{array}{l}\text { Ano de } \\
\text { defesa }\end{array}$ & Objetivo \\
\hline $\begin{array}{l}\text { Silva, L. } \\
\text { N. C. }\end{array}$ & $\begin{array}{l}\text { Situação de Estudo e experimentação } \\
\text { investigativa: Possíveis contribuições } \\
\text { para a aprendizagem de conceitos } \\
\text { químicos }\end{array}$ & TCC & 2018 & $\begin{array}{l}\text { Elaboração e } \\
\text { implementação da } \\
\text { proposta }\end{array}$ \\
\hline $\begin{array}{l}\text { Resende, } \\
\text { R. C. S. }\end{array}$ & $\begin{array}{l}\text { Desenvolvimento de situação de } \\
\text { estudo como facilitadora do processo } \\
\text { de ensino e aprendizagem de ciências } \\
\text { da natureza no } 9^{\circ} \text { ano do ensino } \\
\text { fundamental }\end{array}$ & Dissertação & 2015 & $\begin{array}{l}\text { Elaboração e } \\
\text { implementação da } \\
\text { proposta }\end{array}$ \\
\hline Jesus, D. & $\begin{array}{l}\text { O café nosso de cada dia: Investigação } \\
\text { da influência de uma situação de estudo } \\
\text { no processo de ensino aprendizagem de } \\
\text { ciências da natureza no ensino médio }\end{array}$ & Dissertação & 2016 & $\begin{array}{l}\text { Elaboração e } \\
\text { implementação da } \\
\text { proposta }\end{array}$ \\
\hline $\begin{array}{l}\text { Almeida, } \\
\text { C. L. S }\end{array}$ & $\begin{array}{l}\text { Situação de Estudo na formação de } \\
\text { professores em escolas do campo de } \\
\text { Coaraci-BA }\end{array}$ & Dissertação & 2017 & $\begin{array}{l}\text { Curso de } \\
\text { formação para } \\
\text { professores }\end{array}$ \\
\hline $\begin{array}{l}\text { Vieira, L. } \\
\text { B. G. }\end{array}$ & $\begin{array}{l}\text { Situação de Estudo: Compreensões dos } \\
\text { formadores de professores do ensino de } \\
\text { Ciências }\end{array}$ & Dissertação & 2017 & $\begin{array}{l}\text { Levantamento } \\
\text { bibliográfico }\end{array}$ \\
\hline $\begin{array}{l}\text { Alves, W. } \\
\text { F. S. }\end{array}$ & $\begin{array}{l}\text { Saberes Docentes na Formação Inicial } \\
\text { de Professores de Ciências: (re) } \\
\text { pensando práticas educativas por meio } \\
\text { da Situação de Estudo Ilhéus }\end{array}$ & Dissertação & 2018 & $\begin{array}{l}\text { Elaboração de } \\
\text { uma proposta }\end{array}$ \\
\hline $\begin{array}{l}\text { Peixoto, } \\
\text { C. A. S. }\end{array}$ & $\begin{array}{l}\text { Situação de Estudo na educação } \\
\text { profissional técnica: Distanciamentos e } \\
\text { aproximações }\end{array}$ & Dissertação & 2018 & $\begin{array}{l}\text { Curso de } \\
\text { formação para } \\
\text { professores }\end{array}$ \\
\hline $\begin{array}{l}\text { Sousa, } \\
\text { P. S. }\end{array}$ & $\begin{array}{l}\text { Desenvolvimento profissional docente } \\
\text { no contexto da reconfiguração } \\
\text { curricular pela Situação de Estudo }\end{array}$ & Dissertação & 2018 & $\begin{array}{l}\text { Elaboração de } \\
\text { uma proposta }\end{array}$ \\
\hline $\begin{array}{l}\text { Bomfim, } \\
\text { R. C. }\end{array}$ & $\begin{array}{l}\text { O trabalho colaborativo na interface } \\
\text { universidade-escola: (re)pensando } \\
\text { o currículo por meio da Situação de } \\
\text { Estudo }\end{array}$ & Dissertação & 2019 & $\begin{array}{l}\text { Elaboração e } \\
\text { implementação da } \\
\text { proposta }\end{array}$ \\
\hline Silva, F. & $\begin{array}{l}\text { A Situação de Estudo na formação de } \\
\text { professores do MST: Diálogos com } \\
\text { Henri A. Giroux }\end{array}$ & Dissertação & 2019 & $\begin{array}{l}\text { Curso de } \\
\text { formação para } \\
\text { professores }\end{array}$ \\
\hline
\end{tabular}

Figura 1. Dissertações e TCCs desenvolvidos no contexto do Grupo de Pesquisa em Currículo e Formação de Professores em Ensino em Ciências (GPeCFEC) (continuação)

Fonte: Dados da pesquisa, 2019. 
Nessa primeira análise, percebeu-se que as pesquisas apresentam grupos de objetivos parecidos. Sendo assim, esses objetivos foram classificados em:

Análise de currículo (duas pesquisas) - Algumas das pesquisas indicadas na Figura 1 reservam uma seção de seus textos para tratar do currículo da modalidade de ensino na qual desenvolveram as propostas (Amaral, 2013; Reis, 2016; Bomfim, 2017). Mas, especificamente, as pesquisas de Santos (2016) e Pereira (2017) se dedicaram à análise curricular. Foram desenvolvidas nas modalidades de Educação de Jovens e Adultos (EJA) e do Programa Nacional de Integração da Educação Profissional com a Educação Básica, na modalidade de Jovens e Adultos (PROEJA), respectivamente. Procuraram identificar possíveis contribuições e limitações de uma proposta de reconfiguração curricular nessas modalidades de ensino.

Curso de formação para professores (quatro pesquisas) - Os cursos de formação são geralmente solicitados pelas escolas e elaborados pelo GP, considerando as demandas da escola. De acordo com os objetivos dessas pesquisas, quando os cursos são implementados, busca-se investigar como a proposta pode contribuir para a formação desses professores e como eles podem potencializar o desenvolvimento da proposta a partir de seu contexto. Os cursos de formação e minicursos são elaborados com estrutura representativa de uma proposta de reconfiguração curricular, assim, os participantes vivenciam e ao mesmo tempo constroem a proposta.

Elaboração de uma proposta (três pesquisas) - Essas pesquisas pretenderam analisar as relações mantidas entre os participantes durante a elaboração da proposta.

Elaboração e implementação da proposta de reconfiguração curricular (onze pesquisas) - Esses estudos refletiram sobre o contexto da escola e objetivaram propiciar a aprendizagem dos estudantes sobre determinados conceitos e conteúdos de Ciências. Também se preocuparam em discorrer quanto ao contexto de elaboração, como ocorre a escolha do tema e o papel dos participantes (professores da Educação Básica, licenciandos, mestrandos e professores universitários).

Levantamento Bibliográfico (uma pesquisa) - A pesquisa de Vieira (2017) indica as regiões de maior produção de Situação de Estudo e discute as concepções de formadores de professores que desenvolveram essa proposta.

Cronologicamente, é possível perceber um avanço na apropriação das propostas de reconfiguração diante das necessidades dos contextos em que elas são construídas e implementadas, o qual relaciona-se com o movimento de pesquisa-ação.

O GPeCFEC tem pesquisado sobre currículo e formação de professores no ensino de Ciências com foco na reconfiguração curricular. A cada pesquisa, uma ação é desenvolvida (cursos de formação, elaboração e implementação de uma proposta curricular), promovendo, consequentemente, a reflexão sobre o quê e como foi realizada a ação, seja ela do indivíduo ou do grupo numa investigação colaborativa, crítica e autocrítica. Nesse caso, o problema surge e os participantes apropiam-se dele a fim de resolvê-lo.

Esse ciclo é dado no processo de oscilação entre o investigar a prática e agir sobre 
ela (Tripp, 2005). Entende-se aqui que a pesquisa-ação é o ponto do estudo científico que remete a anomalias e crise na ciência normal (Kuhn, 1996), pois é nesse estado que as dúvidas se instalam e a busca de respostas se tornam inevitáveis, as falhas da teoria estudada são questionadas e executam-se ações até que os questionamentos estejam respondidos. Portanto, desenvolver a pesquisa-ação significa manter-se no estado de crise, de questionamento e essa é claramente uma posição política, crítica e de resistência ao hegemônico. Assim, entende-se, também, que a tentativa de resolução desse problema não significa uma pesquisa com método linear de resolução, mas sim um processo de conjuntos cíclicos que formam uma espiral, como mostra a Figura 2 a seguir:
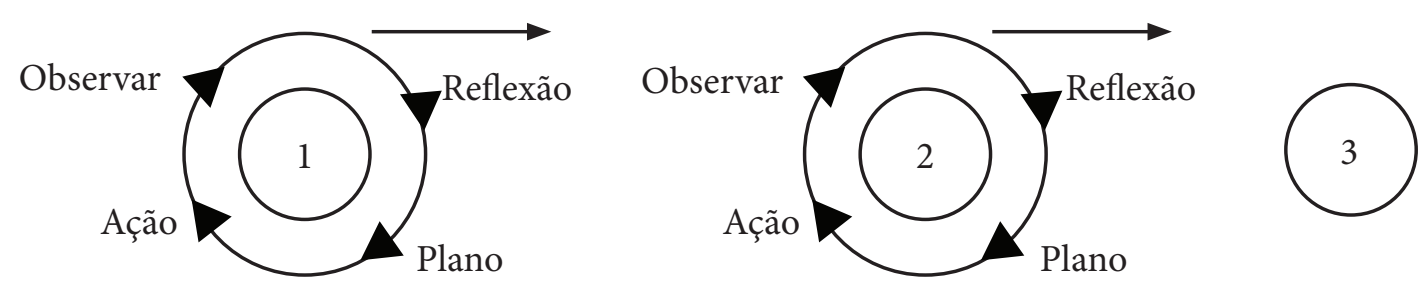

Figura 2. Processo cíclico em espiral da pesquisa ação

Fonte: Zubert-Skerrtitt, p. 20, 2001, adaptação e tradução nossa.

Considera-se que a pesquisa-ação ocorrida no GPeCFEC assemelha-se ao modelo cíclico em espiral (Zubbert-Skerrtitt, 2005), pois a pesquisa-ação, em modelos puramente cíclicos (Tripp, 2005), pode passar a errônea ideia de uma pesquisa interminável em que se repetem os problemas, as ideias e as ações. Assim, a ação é resultado da pesquisa e a próxima pesquisa é resultado da ação, considerando que as pesquisas acadêmicas são concluídas, ou entregues, pois há necessidade em atender a demanda acadêmica. Assim, quando se entrega uma pesquisa, novos questionamentos são levantados para que uma nova investigação, novos planejamentos e novas ações sejam realizados. Para que tal processo de pesquisa se mantenha em ciclo, os sujeitos participantes devem estar envolvidos em todas as etapas do processo de pesquisa numa relação simétrica.

Embora as demais pesquisas tenham mostrado avanços não só teoricamente, mas, também, na prática escolar, a partir da pesquisa de Vieira (2017), inicia-se um importante processo da espiral da pesquisa-ação (Zubert-Skerrtitt, 2005) no interior do grupo de pesquisa. A autora levanta duas principais questões que sugerem a revisão da proposta de reconfiguração curricular desenvolvida no GPeCFEC, vinculadas ao desenvolvimento profissional dos professores envolvidos no processo de construção e implementação das propostas.

Assim, Alves (2018) e Sousa (2018), em continuidade à pesquisa de Vieira (2017), buscaram analisar quais eram as contribuições da proposta de reconfiguração do currículo para a constituição de saberes docentes na formação inicial e de professores da Educação Básica de Física e Química, e como a relação estabelecida entre esses sujeitos influenciou em seus processos de formação permanente e desenvolvimento profissional. Alves (2018) e Sousa (2018), concordam que há uma necessidade de criar comunidades 
investigativas em que os professores da Educação Básica atuem mais efetivamente.

A segunda questão apontada pelo Vieira (2017) é a investigação da dimensão cultural da proposta de reconfiguração curricular. Nisso, Bomfim (2019) e Silva (2019) iniciaram em suas pesquisas o estudo de autores da teoria crítica para estudar o caráter cultural e social das propostas desenvolvidas.

Esses movimentos de continuidade das pesquisas apontam para a pesquisa-ação como uma prática de mudança e progressão de ideias, tanto na teoria quanto em uma prática mais crítica. Direcionando assim a uma compreensão mais complexa da prática social e educacional para que saibam como mudá-la (Kemmis, 2009).

Tendo em vista o processo de estudo das próprias ações pelo qual o grupo de pesquisa em questão acabou vivenciando, é possível refletir sobre três tipos de pesquisaação (Zubert-Skerrtitt, 2005), a saber: Técnico — visa melhorar a prática; Prático — visa compreender todo o processo pelo qual o professor passará por seu desenvolvimento profissional; Empírico - além do melhoramento e compreensão da prática, visa também a transformação e mudança dentro dos limites da realidade, o empoderamento e autoconfiança dos participantes sobre sua capacidade de criar teorias com base em suas próprias práticas.

Nesses três tipos de pesquisa-ação, todas as ações são tomadas colaborativamente dentro de um grupo ou comunidade de pesquisa numa relação entre pares. Nisso, a pesquisa-ação configura-se por "pesquisas que promovem a coletividade e a autorreflexão em que os participantes estão comprometidos a melhorar (1) a racionalidade e a justiça de suas próprias práticas sociais ou educacionais; (2) a compreensão dos participantes sobre essas práticas" (Kemmis \& Mctaggart, 1988 citado em Altrichter, et al. p. 125, 2002, tradução nossa).

Assim, a pesquisa-ação é emancipatória quando busca a mudança das condições existentes, da realidade onde se trabalha e até mesmo do sistema, a fim de superar os elementos que impedem a ação de melhoria, considerando as potencialidades e limitações do contexto em investigação. Nesse sentido, Winter (2005) reforça que a pesquisa-ação é uma forma de investigar e analisar a prática e experiência profissional em movimento contínuo.

\section{Integrando elementos na criação de cenários}

Nesse processo de pesquisa-ação, foram percebidas características nas propostas elaboradas no contexto do GPeCFEC/UESC que se distanciam ou divergem da Situação de Estudo, sendo percebida a emergência de uma nova proposta de reconfiguração curricular. Assim, durante o processo de leitura e releitura dos TCCs e dissertações foram construídas categorias que podem auxiliar na caracterização dessa proposta, a qual é nomeada como Cenário Integrador e representada na Figura 3, por meio de um organograma que sintetiza sua estrutura proposta nesta pesquisa.

Um cenário é um conjunto de elementos que forma uma "circunstância, situação ou condição" (Borba, 2004, p. 261). Por sua vez, a palavra "integrar" suscita o ato de juntar 
elementos e partes, "tornando-se parte integrante" para "completar-se" (Ximenes, 2000, p. 538). Nesse sentido, o Cenário Integrador é uma proposta de reconfiguração curricular que integra conjuntos de elementos que possibilitam o estudo de temas, situações e problemas reais de relevância social. Para a construção dessas propostas contemplam-se dois conjuntos de elementos, a Esfera de Elaboração e a Esfera de Implementação.

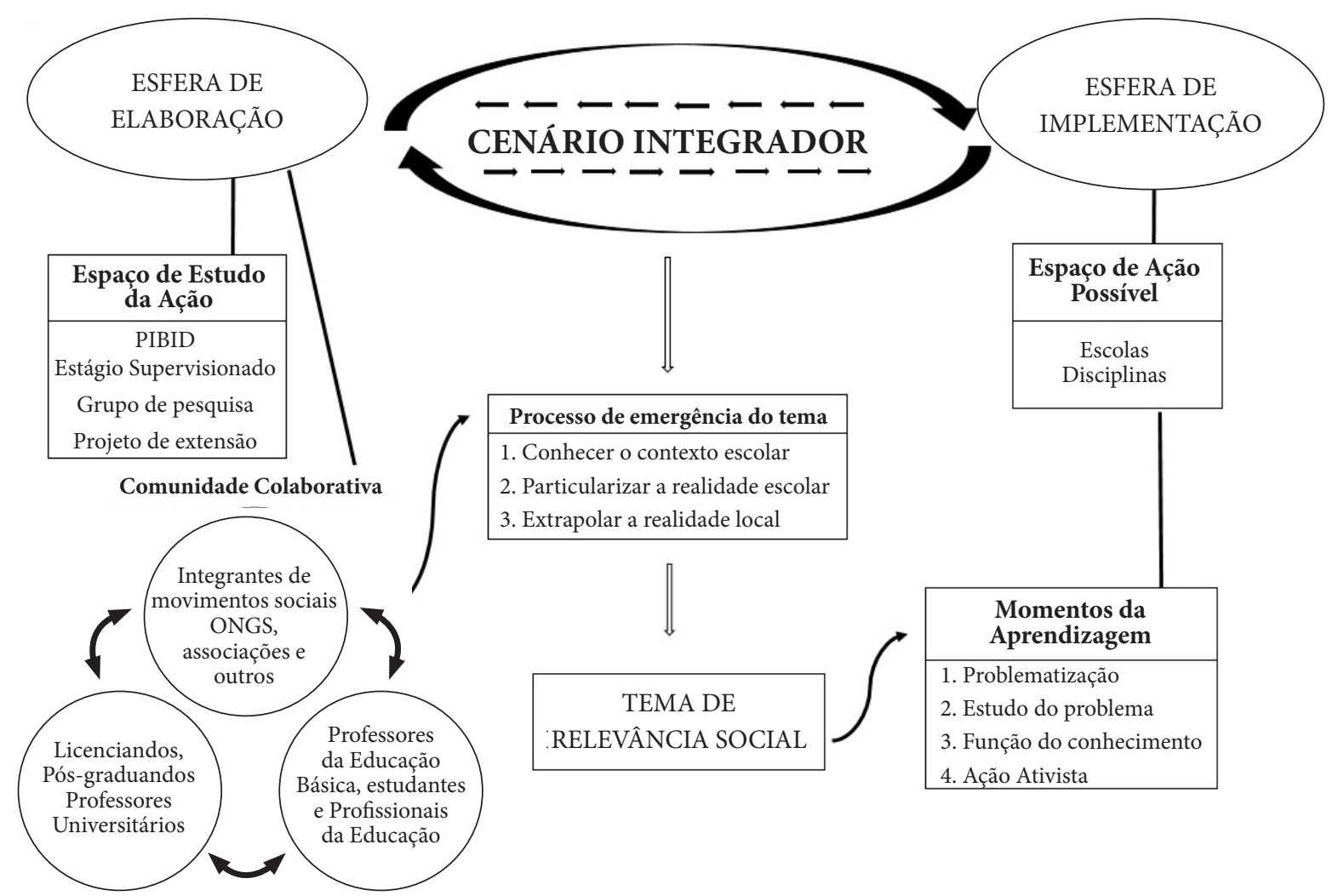

Figura 3. Estrutura da Proposta Curricular Cenário Integrador

Fonte: Dados da pesquisa, 2019.

Para a Esfera de Elaboração, podem ser consideradas as seguintes categorias emergidas: Espaço de elaboração da proposta; Elaboradores (L - Licenciandos, PEB -Professor da Educação Básica, PU — Professor Universitário, PG - Pós-Graduando); e Formação dos participantes. Para a Esfera de Implementação, têm-se as categorias Modalidade de Ensino e Participantes, como exposto na Figura 4. 


\begin{tabular}{|c|c|c|c|c|c|}
\hline \multirow[b]{2}{*}{ Autor } & \multicolumn{3}{|c|}{ Esfera de Elaboração } & \multicolumn{2}{|c|}{ Esfera de Implementação } \\
\hline & $\begin{array}{l}\text { Espaço de } \\
\text { elaboração }\end{array}$ & Elaboradores & $\begin{array}{l}\text { Formação dos } \\
\text { elaboradores }\end{array}$ & $\begin{array}{l}\text { Modalidade } \\
\text { de Ensino }\end{array}$ & Participantes \\
\hline Amaral, G. & PIBID & $\mathrm{L}-\mathrm{PEB}-\mathrm{PU}$ & Química & $\begin{array}{l}\text { Curso } \\
\text { técnico }\end{array}$ & Estudantes \\
\hline $\begin{array}{l}\text { Fernandes } \\
\text { F. G. }\end{array}$ & Estágio & $\mathrm{L}-\mathrm{PEB}-\mathrm{PU}$ & $\begin{array}{l}\text { Química, Física, } \\
\text { Biologia }\end{array}$ & $\begin{array}{l}\text { Curso } \\
\text { técnico }\end{array}$ & Estudantes \\
\hline $\begin{array}{l}\text { Pinto, J. G. } \\
\text { R. }\end{array}$ & PIBID & $\mathrm{L}-\mathrm{PEB}-\mathrm{PU}$ & Química & $\begin{array}{l}\text { Curso } \\
\text { técnico }\end{array}$ & Estudantes \\
\hline $\begin{array}{l}\text { Bomfim, R. } \\
\text { C. }\end{array}$ & GPeCFEC & $\mathrm{L}-\mathrm{PEB}-\mathrm{PU}$ & Química & $\begin{array}{l}\text { Ensino } \\
\text { fundamental }\end{array}$ & Estudantes \\
\hline $\begin{array}{l}\text { Pimenta, } \\
\text { S. S. }\end{array}$ & GPeCFEC & $\mathrm{L}-\mathrm{PEB}-\mathrm{PU}$ & Química & $\begin{array}{l}\text { Curso } \\
\text { técnico }\end{array}$ & Estudantes \\
\hline $\begin{array}{l}\text { Reis, C. M. } \\
\text { R. }\end{array}$ & PIBID & $\mathrm{L}-\mathrm{PEB}-\mathrm{PU}$ & Química & EJA & Estudantes \\
\hline $\begin{array}{l}\text { Guimarães, } \\
\text { T. S. }\end{array}$ & $\begin{array}{l}\text { Escola - } \\
\text { GPeCFEC }\end{array}$ & $L-P U-P G$ & $\begin{array}{l}\text { Química, Física, } \\
\text { Biologia }\end{array}$ & $\begin{array}{l}\text { Complexo } \\
\text { Integrado de } \\
\text { Educação }\end{array}$ & Estudantes \\
\hline $\begin{array}{l}\text { Sampaio, } \\
\text { T. S. }\end{array}$ & $\begin{array}{l}\text { GPeCFEC } \\
\text { - Escola } \\
\text { (EJA) }\end{array}$ & $\mathrm{L}-\mathrm{PEB}-\mathrm{PU}$ & $\begin{array}{l}\text { Química, } \\
\text { Biologia, } \\
\text { Agronomia }\end{array}$ & Não se aplica & Não se aplica \\
\hline Silva, U. K. & GPeCFEC & $\mathrm{L}-\mathrm{PEB}-\mathrm{PU}$ & $\begin{array}{l}\text { Química, } \\
\text { Biologia }\end{array}$ & $\begin{array}{l}\text { Ensino } \\
\text { médio }\end{array}$ & Estudantes \\
\hline $\begin{array}{l}\text { Silva, L. N. } \\
\text { C. }\end{array}$ & GPeCFEC & $\mathrm{L}-\mathrm{PEB}-\mathrm{PU}$ & Química & $\begin{array}{l}\text { Ensino } \\
\text { médio }\end{array}$ & Estudantes \\
\hline $\begin{array}{l}\text { Resende, R. } \\
\text { C. S. }\end{array}$ & Escola & $\begin{array}{l}\text { PEB - PG - } \\
\text { PU }\end{array}$ & $\begin{array}{l}\text { Química, Física, } \\
\text { Biologia }\end{array}$ & $\begin{array}{l}\text { Ensino } \\
\text { fundamental }\end{array}$ & Estudantes \\
\hline Jesus, D. & $\begin{array}{l}\text { Programa } \\
\text { de Pós- } \\
\text { Graduação }\end{array}$ & $\begin{array}{l}\text { PEB - PG - } \\
\text { PU }\end{array}$ & Química, Física & $\begin{array}{l}\text { Ensino } \\
\text { médio }\end{array}$ & Estudantes \\
\hline $\begin{array}{l}\text { Almeida, C. } \\
\text { L. S }\end{array}$ & $\begin{array}{l}\text { Escola - } \\
\text { GPeCFEC }\end{array}$ & $\begin{array}{l}\mathrm{L}-\mathrm{PG}-\mathrm{PU}- \\
\mathrm{PE}\end{array}$ & $\begin{array}{l}\text { Química, } \\
\text { Biologia, } \\
\text { Pedagogia }\end{array}$ & $\begin{array}{l}\text { Educação do } \\
\text { campo }\end{array}$ & $\begin{array}{l}\text { Professores da } \\
\text { EB }\end{array}$ \\
\hline $\begin{array}{l}\text { Alves, W. } \\
\text { F. S. }\end{array}$ & Estágio & $\begin{array}{l}\mathrm{L}-\mathrm{PEB}-\mathrm{PU} \\
-\mathrm{PG}\end{array}$ & $\begin{array}{l}\text { Química, Física, } \\
\text { Biologia }\end{array}$ & Não se aplica & Não se aplica \\
\hline
\end{tabular}

Figura 4. Esferas das propostas de reconfiguração desenvolvidas no contexto do GPeCFEC (continua) 


\begin{tabular}{|l|l|l|l|l|l|}
\hline \multicolumn{2}{|l|}{ Esfera de Elaboração } & \multicolumn{2}{l|}{ Esfera de Implementação } \\
\hline Autor & $\begin{array}{l}\text { Espaço de } \\
\text { elaboração }\end{array}$ & Elaboradores & $\begin{array}{l}\text { Formação dos } \\
\text { elaboradores }\end{array}$ & $\begin{array}{l}\text { Modalidade } \\
\text { de Ensino }\end{array}$ & Participantes \\
\hline $\begin{array}{l}\text { Peixoto, C. } \\
\text { A. S. }\end{array}$ & $\begin{array}{l}\text { GPeCFEC } \\
- \text { Instituto } \\
\text { Federal }\end{array}$ & PEB - PG & $\begin{array}{l}\text { Química, } \\
\text { Biologia, } \\
\text { Pedagogia }\end{array}$ & Não se aplica & Não se aplica \\
\hline Sousa, P. S. & Estágio & $\begin{array}{l}\text { L-PEB - PU } \\
- \text { PG }\end{array}$ & $\begin{array}{l}\text { Química, Física, } \\
\text { Biologia }\end{array}$ & Não se aplica & Não se aplica \\
\hline $\begin{array}{l}\text { Bomfim, R. } \\
\text { C. }\end{array}$ & $\begin{array}{l}\text { Escola - } \\
\text { GPeCFEC }\end{array}$ & $\begin{array}{l}\text { L-PEB - PU } \\
- \text { PG }\end{array}$ & $\begin{array}{l}\text { Química, Física, } \\
\text { Biologia }\end{array}$ & $\begin{array}{l}\text { Complexo } \\
\text { Integrado de } \\
\text { Educação }\end{array}$ & Estudantes \\
\hline $\begin{array}{l}\text { Silva, F. N. } \\
\text { S. }\end{array}$ & GPeCFEC & $\begin{array}{l}\text { L - PG -PU } \\
- \text { D }\end{array}$ & $\begin{array}{l}\text { Química, } \\
\text { Biologia, } \\
\text { Pedagogia }\end{array}$ & $\begin{array}{l}\text { Centro } \\
\text { Integrado }\end{array}$ & $\begin{array}{l}\text { Direção, } \\
\text { coordenação e } \\
\text { PEB }\end{array}$ \\
\hline
\end{tabular}

Figura 4. Esferas das propostas de reconfiguração desenvolvidas no contexto do GPeCFEC (continuação)

Fonte: Dados da pesquisa, 2019.

As variáveis que constituem a Esfera de Elaboração apontam para a existência de um Espaço de Estudo da Ação e uma Comunidade Colaborativa. O Espaço de Estudo da Ação é o universo que propicia a construção do Cenário Integrador porque: 1) tem acesso a instituições escolares e acadêmicas (Espaços de Ação Possível) previstas por seu projeto; 2) conta com espaços físicos para realização de encontros e reuniões; 3) facilita o relacionamento e comunicação entre indivíduos dispostos a reconfigurar o currículo escolar constituindo uma Comunidade Colaborativa.

As pesquisas analisadas apontam para a necessidade de construir propostas de reconfiguração em colaboração com diferentes atores de diferentes formações, pois diversas dificuldades foram encontradas quando as propostas foram desenvolvidas fora desse formato. Assim, adotamos que a Comunidade Colaborativa, pode ser composta por quaisquer indivíduos que tenham relação estudantil, acadêmica, profissional ou colaborativa com uma escola, sendo estes: estudantes, licenciandos, pós-graduandos, professores da Educação Básica, professores universitários, profissionais da educação, integrantes de movimentos sociais, membros de ONGs, integrantes de associações de bairro e outros, desde que estejam relacionados e possam ajudar no desdobramento do tema escolhido. Desse modo, o desenvolvimento da proposta pode criar conexões entre a universidade, a escola e a sociedade, como é mostrado na Figura 5.

Uma comunidade é constituída pelo interesse em comum dos indivíduos. Assim, a Comunidade Colaborativa caracteriza-se pela integração de indivíduos prontos a reconfigurar o currículo, para promover uma educação e um ensino de qualidade, preocupados com fatores sociais, históricos, políticos e econômicos, para além dos 
conteúdos científicos.

Figura 5. Comunidade colaborativa

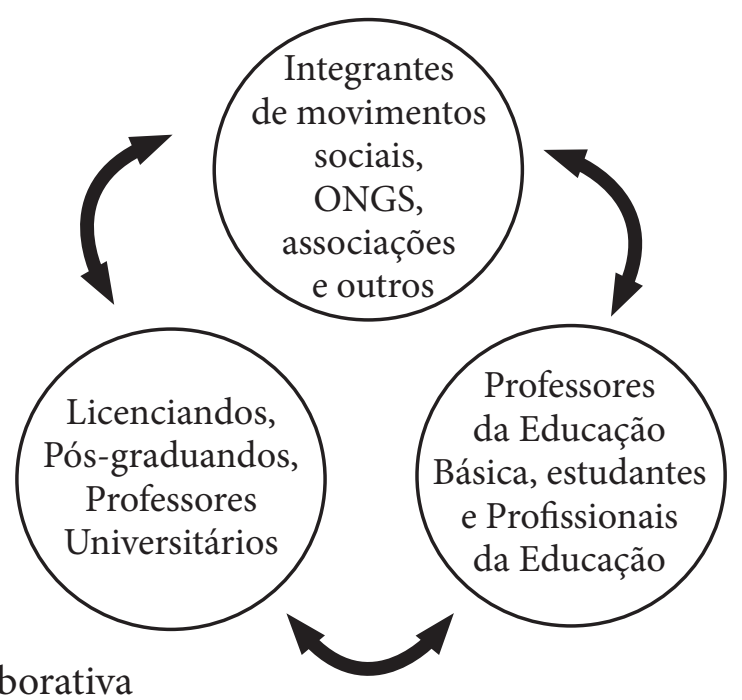

Fonte: Dados da pesquisa, 2019.

É possível que a proposta de reconfiguração curricular alcance maior complexidade do tema a ser desenvolvido, devido ao fato de os integrantes dessa comunidade possuírem diferentes experiências nas áreas sociais e acadêmicas. E que também estejam dispostos a trabalhar em favor da reconfiguração do currículo, pois "as lutas na educação e à sua volta podem ter efeito na sociedade como um todo" (Apple, 2017a, p. 37).

No entanto, salienta-se que nem sempre será possível a participação de todos os sujeitos da comunidade de elaboração, pois cada um cumpre com deveres e agendas diferentes, o que pode dificultar o encontro entre todos. Ainda, a falta de um desses representantes não desconfigura a Comunidade Colaborativa, tendo em vista sua definição apontada acima.

As principais funções dessa comunidade são: a) promover espaços de ação possível; b) investigar a emergência de um tema de relevância social e científica (com as características do tema) a partir do contexto social da escola e do entorno dela; c) construir a proposta de reconfiguração curricular, preocupando-se em vincular os conteúdos e conceitos ao tema escolhido e engajar-se criticamente no estudo desses temas; d) conectar práticas educacionais às questões sociais de cunho local, regional, nacional e global (Apple, 2017a); e) estar disponível para desenvolver os interesses não somente pedagógicos, mas também a agir em apoio a grupos e movimentos sociais (Apple, 2017a).

Tendo em vista essas funções é importante saber que as questões educacionais são geralmente originadas em problemas estruturais e pouco consideram uma perspectiva crítica, pois os deveres e os diversos problemas enfrentados na educação ocupam grande parte de suas tarefas, tempo e atenção dos educadores (Apple, 1989). Então, se os educadores não se encontrarem, ao menos em parte, como responsáveis da tradição crítica, e responsáveis pelo o que é construído institucionalmente e culturalmente, dificilmente há de se conseguir reconstruir esse sistema (Apple, 2006). 
Assim, diante do papel da universidade e do seu compromisso em desenvolver ensino, pesquisa e extensão, essa tem se apresentado como fomentadora também da reconfiguração curricular tendo em vista que nos TCCs e dissertações analisadas foram identificados os seguintes espaços de estudo da ação: o Programa Institucional de Bolsa de Iniciação à Docência (PIBID); o Estágio Supervisionado; o grupo de pesquisa. Esses espaços atendem a diferentes objetivos, mas são similares quanto à relação mantida entre universidade e escola por meio de seus participantes.

O PIBID, no qual essas pesquisas foram realizadas, foi o subprojeto de Química. Nesse espaço, os participantes têm diferentes níveis de formação, sendo licenciandos, professores da educação básica e professores universitários, todos com formação inicial em licenciatura em Química. Logo, as propostas elaboradas centraram-se nessa disciplina, mesmo que outras disciplinas sejam envolvidas.

O Estágio Supervisionado na Licenciatura em Química também prevê a relação mútua entre professores de diferentes níveis de formação. Porém, segundo as pesquisas analisadas, as comunidades de elaboração foram mais diversificadas com a participação de sujeitos de diferentes áreas de formação, sendo isso possível porque nesse espaço foram desenvolvidos projetos considerando o educar pela pesquisa conforme apontam Massena e Brito (2015), Alves (2018) e Sousa (2018) em seus textos.

O espaço do GPeCFEC, por sua vez, é o ponto de encontro para a elaboração dessas pesquisas. É no interior do grupo que são produzidas as propostas de reconfiguração curricular, seja no âmbito de projetos de pesquisa, com a participação de bolsistas de Iniciação Científica (IC), professores universitários (estes últimos também responsáveis por gerenciar o grupo), licenciandos no desenvolvimento de TCC e mestrandos no desenvolvimento de dissertação. Ogrupo, em sua maioria, é constituído por participantes com formação em Licenciatura em Química, mas, também, conta com a participação de licenciados em Física, Biologia e Pedagogia.

O GPeCFEC tem constituído parcerias com escolas da região, o que permite a presença do grupo dentro da escola, facilitando a participação de professores da educação básica de diferentes formações na Comunidade Colaborativa, tanto no processo de elaboração quanto na implementação das propostas de reconfiguração curricular. Essas escolas atuam em diferentes modalidades de educação e apresentam estruturas curriculares diferenciadas das escolas regulares (Resende, 2013; Bomfim, 2016), sendo essa uma característica da Esfera de Implementação, como apontado na Figura 5.

A Esfera de Implementação é o conjunto de elementos envolvidos no ambiente escolar ou acadêmico onde o currículo será reconfigurado. Nessa esfera, deve existir um Espaço de ação possível, isto é, "espaços em que ações mais progressistas e antihegemônicas possam continuar" ou serem iniciadas (Apple, 2017, p. 76) para que a proposta e a pesquisa desenvolvidas alcancem transformações e sejam creditadas. A análise das propostas desenvolvidas em diferentes modalidades de ensino aponta predisposição para uma reconfiguração curricular que seja desenvolvida a partir de temas, configurando-se, assim, espaços de ação possível. 
Na modalidade em Ensino Técnico (Amaral, 2013; Pimenta, 2016), os alunos devem escolher uma carreira no primeiro ano do ensino médio e, nesse período, estudam somente disciplinas voltadas à carreira. Por exemplo, no Curso Técnico de Biocombustíveis, as disciplinas ofertadas são Química Geral, Analítica, Inorgânica e Orgânica, sendo que, ao fim do curso, os alunos devem apresentar um TCC relacionado à temática de biocombustíveis.

Na modalidade Educação de Jovens e Adultos (EJA) (Reis, 2016; Sampaio, 2017), o currículo está pautado em Tempos Formativos, Eixos Temáticos e Temas Geradores, e as disciplinas são agrupadas por áreas do conhecimento.

No Complexo Integrado de Educação de Itabuna (Guimarães, 2017), trabalha-se a educação escolar integral e seus horários são divididos em quatro tempos durante o diurno. Assim, o primeiro e terceiro tempos são dedicados às disciplinas, enquanto o segundo e quarto tempos são reservados às Estações do Saber, espaços organizados por meio de temas no intuito de trabalhar interdisciplinarmente com turmas multisseriadas. A multisseriação também é uma realidade nas escolas de Educação do Campo (Almeida, 2017) e no Centro Integrado Florestan Fernandes (Silva, 2019) embora estes se configurem em contextos particulares.

De acordo com o apresentado, a parcela de cultura exibida nas propostas de reconfiguração curricular é definida e transformada pelas esferas de elaboração e de implementação, portanto, o contexto e os indivíduos que constituem essas esferas atuam na seleção dos conteúdos do ensino, aqueles tácitos e explícitos (Sacristán, 1998).

As duas esferas constituem características importantes para a escolha de temas que tenham relevância social e que sejam propícios para o ensino de Ciências. Assim, os integrantes da Comunidade Colaborativa devem transitar de uma esfera para outra, dinamizando o estudo da teoria e a prática, pois a teoria não tem sentido sem as lutas reais enfrentadas na escola (Apple, 2017).

\section{O Processo de seleção do tema em Cenários Integradores}

$\mathrm{Na}$ abordagem por temas para realização de uma proposta, é necessário que haja um estudo teórico do tema emergente e das estratégias e métodos adotados no planejamento, mas, sobretudo, é necessário conhecer intimamente o espaço escolar, as situações problemáticas desse ambiente e a realidade de seu entorno.

$\mathrm{Na}$ Figura 6 a seguir, são apresentados os temas escolhidos, os títulos das propostas, as justificativas dos autores pela escolha do tema, as disciplinas em que as propostas foram concentradas e estratégias e instrumentos utilizados nas aulas conforme apontados pelas pesquisas que objetivaram elaborar e implementar a proposta de reconfiguração e cursos de formação. As pesquisas que tiveram como objetivo a análise de currículo e levantamento bibliográfico não estão listadas na Figura 6, pois não desenvolveram uma proposta de reconfiguração curricular. 


\begin{tabular}{|c|c|c|c|c|}
\hline Autor & Título (Tema) & Justificativa & Disciplina & $\begin{array}{l}\text { Estratégias e } \\
\text { Instrumentos }\end{array}$ \\
\hline $\begin{array}{l}\text { Amaral, } \\
\text { G. }\end{array}$ & $\begin{array}{l}\text { Alisantes: } \\
\text { Uma forma } \\
\text { de ensinar } \\
\text { concentração }\end{array}$ & $\begin{array}{l}\text {-Conteúdos científicos } \\
\text {-Futura atuação } \\
\text { profissional } \\
\text {-Considera o currículo }\end{array}$ & Química & $\begin{array}{l}\text { Conversa, questionário, } \\
\text { pesquisa, aula expositiva, } \\
\text { Júri Químico, atividade } \\
\text { experimental, resumo, } \\
\text { prova. }\end{array}$ \\
\hline $\begin{array}{l}\text { Fernandes } \\
\text { F. G. }\end{array}$ & $\begin{array}{l}\text { Produtos de } \\
\text { limpeza }\end{array}$ & $\begin{array}{l}\text {-Conteúdos científicos } \\
\text {-Futura atuação } \\
\text { profissional } \\
\text {-Considera o currículo }\end{array}$ & Química & $\begin{array}{l}\text { Questionário, palestra, } \\
\text { texto, aula expositiva, } \\
\text { vídeos, avaliação oral, } \\
\text { exercícios. }\end{array}$ \\
\hline $\begin{array}{l}\text { Pinto, J. } \\
\text { G. R. }\end{array}$ & $\begin{array}{l}\text { Automedicação, } \\
\text { um mal } \\
\text { necessário? }\end{array}$ & $\begin{array}{l}\text {-Tema atual } \\
\text {-Relevância social } \\
\text {-Futura atuação } \\
\text { profissional } \\
\text {-Considera o currículo }\end{array}$ & Química & $\begin{array}{l}\text { Texto, vídeo, Jigsaw, } \\
\text { questionário, TV } \\
\text { pendrive, aula } \\
\text { expositiva, debate, } \\
\text { experimento, produção } \\
\text { textual, exercícios, } \\
\text { prova. }\end{array}$ \\
\hline $\begin{array}{l}\text { Bomfim, } \\
\text { R. C. }\end{array}$ & Automedicação & $\begin{array}{l}\text {-Conteúdos científicos } \\
\text { interdisciplinares } \\
\text {-Questões } \\
\text { socioculturais }\end{array}$ & $\begin{array}{l}\text { Química, } \\
\text { Biologia }\end{array}$ & $\begin{array}{l}\text { Questionário, aula } \\
\text { expositiva, aula } \\
\text { expositiva-dialogada, } \\
\text { vídeos, discussão, leitura } \\
\text { de bula, construção de } \\
\text { cartazes, resolução de } \\
\text { exercícios. }\end{array}$ \\
\hline $\begin{array}{l}\text { Pimenta, } \\
\text { S. S. }\end{array}$ & $\begin{array}{l}\text { A ciência que } \\
\text { os cachos } \\
\text { precisam: No } \\
\text { poo e Low poo }\end{array}$ & $\begin{array}{l}\text {-Tema atual } \\
\text {-Contexto social } \\
\text {-Conteúdos científicos } \\
\text { interdisciplinares }\end{array}$ & $\begin{array}{l}\text { Química, } \\
\text { Biologia, } \\
\text { Física }\end{array}$ & $\begin{array}{l}\text { Roda de conversa, aula } \\
\text { expositiva, exposição } \\
\text { de imagens, análise de } \\
\text { rótulos, experimento, } \\
\text { relatório, produção } \\
\text { textual, exercício, } \\
\text { prova. }\end{array}$ \\
\hline $\begin{array}{l}\text { Reis, C. } \\
\text { M. R. }\end{array}$ & $\begin{array}{l}\text { Eu, a química } \\
\text { e o lixo: tudo a } \\
\text { ver }\end{array}$ & $\begin{array}{l}\text {-Relevância social } \\
\text {-Contexto local }\end{array}$ & $\begin{array}{l}\text { Química, } \\
\text { Artes, Física, } \\
\text { Biologia. } \\
\text { Matemática. }\end{array}$ & $\begin{array}{l}\text { Questionário, filmes, } \\
\text { cartaz, aula expositiva, } \\
\text { vídeos, experimento, } \\
\text { prova exercícios, } \\
\text { elaboração de panfletos, } \\
\text { confecção de materiais, } \\
\text { apresentação oral, } \\
\text { trabalho em grupo, } \\
\text { exposição. }\end{array}$ \\
\hline
\end{tabular}

Figura 6. Estruturantes das propostas de reconfiguração curricular elaboradas (continua) 


\begin{tabular}{|c|c|c|c|c|}
\hline Autor & Título (Tema) & Justificativa & Disciplina & $\begin{array}{l}\text { Estratégias e } \\
\text { Instrumentos }\end{array}$ \\
\hline $\begin{array}{l}\text { Guimarães, } \\
\text { T. S. }\end{array}$ & $\begin{array}{l}\text { A Química do } \\
\text { Chocolate e o } \\
\text { Cacau de Jorge } \\
\text { Amado }\end{array}$ & $\begin{array}{l}\text {-Contexto regional } \\
\text {-Conteúdo científico } \\
\text { interdisciplinar e de } \\
\text { humanidades } \\
\text {-Questões sociais, } \\
\text { culturais e } \\
\text { econômicas }\end{array}$ & $\begin{array}{l}\text { Química, } \\
\text { Literatura, } \\
\text { Biologia, } \\
\text { História, } \\
\text { Geografia. }\end{array}$ & $\begin{array}{l}\text { Questionário, diário de } \\
\text { bordo, leitura de livro } \\
\text { de literatura, dinâmica, } \\
\text { discussão, jogo didático, } \\
\text { relato. }\end{array}$ \\
\hline $\begin{array}{l}\text { Sampaio, } \\
\text { T. S. }\end{array}$ & Ecologia & $\begin{array}{l}\text {-Conteúdos } \\
\text { científicos } \\
\text { interdisciplinares } \\
\text {-Considera o } \\
\text { currículo } \\
\text {-Relevância social }\end{array}$ & $\begin{array}{l}\text { Química, } \\
\text { Biologia, } \\
\text { Física e } \\
\text { Matemática }\end{array}$ & $\begin{array}{l}\text { Pesquisa, Exposição } \\
\text { oral, fotografia, cartazes, } \\
\text { produção textual, } \\
\text { dramatização, debate, } \\
\text { jornal. }\end{array}$ \\
\hline Silva, U. K. & $\begin{array}{l}\text { Água do Rio } \\
\text { Almada }\end{array}$ & $\begin{array}{l}\text {-Contexto regional } \\
\text {-Conceitos } \\
\text { científicos } \\
\text { interdisciplinares } \\
\text {-Conteúdos de } \\
\text { humanidades }\end{array}$ & $\begin{array}{l}\text { Química, } \\
\text { Biologia, } \\
\text { Matemática, } \\
\text { História, } \\
\text { Geografia, } \\
\text { Sociologia } \\
\text { Português }\end{array}$ & $\begin{array}{l}\text { Diálogo, desenho, } \\
\text { maquete, roteiro, análise } \\
\text { de rótulos, exposição de } \\
\text { imagens, experimento, } \\
\text { jigsaw, texto, discussão. }\end{array}$ \\
\hline $\begin{array}{l}\text { Silva, L. N. } \\
\text { C. }\end{array}$ & $\begin{array}{l}\text { A qualidade } \\
\text { da água do rio } \\
\text { Cachoeira }\end{array}$ & $\begin{array}{l}\text {-Contexto local e } \\
\text { regional } \\
\text {-Conteúdos } \\
\text { científicos }\end{array}$ & Química & $\begin{array}{l}\text { Questionário, vídeo, } \\
\text { discussão, aula } \\
\text { dialogada, narrativa, } \\
\text { atividade em grupo, } \\
\text { saída de campo, } \\
\text { experimentação. }\end{array}$ \\
\hline $\begin{array}{l}\text { Resende, R. } \\
\text { C. S. }\end{array}$ & $\begin{array}{l}\text { Alimentos: } \\
\text { produção e } \\
\text { consumo }\end{array}$ & $\begin{array}{l}\text {-Cotidiano dos } \\
\text { estudantes } \\
\text {-Conteúdos } \\
\text { científicos } \\
\text { interdisciplinares }\end{array}$ & $\begin{array}{l}\text { Química, } \\
\text { Física e } \\
\text { Biologia }\end{array}$ & $\begin{array}{l}\text { Discussões, leituras, } \\
\text { análise de vídeos e } \\
\text { de rótulos, produção } \\
\text { de alimentos, filme, } \\
\text { produção textual, } \\
\text { avaliação, lanche. }\end{array}$ \\
\hline Jesus, D. & $\begin{array}{l}\text { O café nosso de } \\
\text { cada dia }\end{array}$ & $\begin{array}{l}\text {-Cotidiano dos } \\
\text { estudantes } \\
\text {-Conteúdos } \\
\text { históricos e } \\
\text { científicos } \\
\text { interdisciplinares } \\
\text {-Relevância global }\end{array}$ & $\begin{array}{l}\text { Química, } \\
\text { Física e } \\
\text { Biologia, } \\
\text { História }\end{array}$ & $\begin{array}{l}\text { História, discussão, } \\
\text { vídeo, trabalho em } \\
\text { grupo, experimento, } \\
\text { atividade prática, } \\
\text { jigsaw, aula expositiva, } \\
\text { confecção de gráficos, } \\
\text { degustação, roteiro, } \\
\text { relatório, exposição de } \\
\text { imagens }\end{array}$ \\
\hline
\end{tabular}

Figura 6. Estruturantes das propostas de reconfiguração curricular elaboradas (continua) 


\begin{tabular}{|c|c|c|c|c|}
\hline Autor & Título (Tema) & Justificativa & Disciplina & $\begin{array}{l}\text { Estratégias e } \\
\text { Instrumentos }\end{array}$ \\
\hline $\begin{array}{l}\text { Almeida, } \\
\text { C. L. S }\end{array}$ & $\begin{array}{l}\text { Geração e } \\
\text { gerenciamento de } \\
\text { resíduos sólidos } \\
\text { provenientes } \\
\text { das atividades } \\
\text { humanas }\end{array}$ & $\begin{array}{l}\text {-Cotidiano dos } \\
\text { estudantes } \\
\text {-Conteúdos científicos }\end{array}$ & $\begin{array}{l}\text { Química, } \\
\text { Física e } \\
\text { Biologia, } \\
\text { Artes. }\end{array}$ & $\begin{array}{l}\text { Vídeo, discussão, } \\
\text { atividades práticas } \\
\text { (reciclagem } \\
\text { artesanal de papel } \\
\text { e construção de } \\
\text { uma composteira } \\
\text { doméstica), oficina. }\end{array}$ \\
\hline $\begin{array}{l}\text { Peixoto, C. } \\
\text { A. S. }\end{array}$ & Sustentabilidade & $\begin{array}{l}\text {-Conteúdos científicos } \\
\text { interdisciplinares }\end{array}$ & $\begin{array}{l}\text { Química, } \\
\text { Física, Artes, } \\
\text { Biologia, } \\
\text { Geografia, } \\
\text { Português, } \\
\text { Espanhol }\end{array}$ & $\begin{array}{l}\text { Dinâmica, diálogo, } \\
\text { textos. }\end{array}$ \\
\hline \multirow{2}{*}{$\begin{array}{l}\text { Bomfim, } \\
\text { R. C. }\end{array}$} & $\begin{array}{l}\text { 1.Movimente-se } \\
\text { com as Ciências }\end{array}$ & $\begin{array}{l}\text {-Relevância local } \\
\text {-Conteúdos científicos } \\
\text { interdisciplinares }\end{array}$ & $\begin{array}{l}\text { Química, } \\
\text { Física e } \\
\text { Biologia }\end{array}$ & $\begin{array}{l}\text { 1. Experimento, } \\
\text { discussão, texto, } \\
\text { construção tabela, } \\
\text { construção de } \\
\text { pirâmide alimentar, } \\
\text { relatos. }\end{array}$ \\
\hline & $\begin{array}{l}\text { 2.Dê um like na } \\
\text { vida: drogas lícitas }\end{array}$ & $\begin{array}{l}\text {-Conteúdos } \\
\text { interdisciplinares } \\
\text { científicos e de } \\
\text { humanidades } \\
\text {-Questões sociais, } \\
\text { políticas e econômicas }\end{array}$ & $\begin{array}{l}\text { Química, } \\
\text { Física e } \\
\text { Biologia }\end{array}$ & $\begin{array}{l}\text { 2. Trecho de série, } \\
\text { discussão, relatos, } \\
\text { atividade em grupo, } \\
\text { júri, texto, vídeo, } \\
\text { documentário, stand } \\
\text { em feira de ciências. }\end{array}$ \\
\hline $\begin{array}{l}\text { Silva, F. N. } \\
\text { S. }\end{array}$ & $\begin{array}{l}\text { Situação de Estudo } \\
\text { na Formação de } \\
\text { educadoras/es do } \\
\text { MST: repensando o } \\
\text { currículo escolar a } \\
\text { partir da temática } \\
\text { alimentação } \\
\text { saudável }\end{array}$ & $\begin{array}{l}\text {-Relevância local } \\
\text {-Vivência dos } \\
\text { professores } \\
\text {-Conteúdos científicos } \\
\text { interdisciplinares } \\
\text {-Contexto social } \\
\text {-Questões culturais }\end{array}$ & $\begin{array}{l}\text { Química e } \\
\text { Biologia }\end{array}$ & $\begin{array}{l}\text { Leitura, discussão } \\
\text { e socialização em } \\
\text { grupo, textos, vídeo, } \\
\text { experimentos, } \\
\text { produções textuais. }\end{array}$ \\
\hline
\end{tabular}

Figura 6. Estruturantes das propostas de reconfiguração curricular elaboradas (continuação)

Fonte: Dados da pesquisa, 2019.

Segundo a Figura 6, os temas mais frequentes foram: meio ambiente, alimentos e produtos cosméticos. Percebe-se que grande parte dos temas escolhidos consideram pelo menos três aspectos, tais como o contexto dos participantes, temas que suscitam conteúdos desejados e o currículo escolar.

Quando novas abordagens são sugeridas para professores da Educação Básica, uma das preocupações que surge é quanto ao segmento do currículo, sendo comum 
solicitarem que os conteúdos sejam mantidos. Também surgem preocupações relacionadas ao quão prolongado é o período de implementação da proposta e quando pode ser implementada, pois a escola cumpre horários, prazos de entrega, períodos de realização de provas e outras atividades. Em relação a esses aspectos, Sacristán (1998) relembra bem que:

O professor/a não trabalha no vazio, mas dentro de organizações que regulam as práticas: as condições da escolarização, a regulação do currículo realizada fora das aulas e a flexibilidade para desenvolver o trabalho dos docentes. A autonomia profissional possível para os professores/as de uma escola reside no terreno fronteiriço que gera a dialética entre as pressões externas e a prática que é possível elaborar no marco organizativo de cada escola. Um terreno que será ou não aproveitável em função da formação do professorado e segundo o grau de agremiação entre os indivíduos (Sacristán, 1998, p. 207).

Portanto, durante a elaboração de propostas de reconfiguração curricular é necessário considerar a realidade da escola e do professor colaborador da Educação Básica quanto aos condicionamentos de seu exercício profissional (Sacristán, 1998).

Nesse sentido, pensando na dinâmica das escolas, as propostas implementadas na Educação Básica tiveram duração de um a quatro meses, durando em média uma unidade escolar, sendo geralmente divididas em quatro (4) momentos. Também, em algumas propostas o tema foi escolhido a partir dos conteúdos previstos no plano anual do professor, para que o currículo da disciplina pudesse ser concluído. Mesmo nesses casos, considera-se a reconfiguração do currículo, pois a sequência dos conteúdos foi alterada para serem discutidos interdisciplinarmente. Além disso, esses conteúdos são introduzidos por meio de uma larga variedade de estratégias e instrumentos que ajudam a discutir dimensões sociais e políticas relacionadas ao tema, como os vídeos, leitura de textos e a própria discussão.

Em algumas ocasiões houve uma certa dificuldade para que os professores da Educação Básica participassem efetivamente e se apropriassem do desenvolvimento da reconfiguração curricular, mas é importante ressaltar que nos casos em que a escola estava envolvida em atividades e projetos mais amplos, e o programa escolar foi respeitado na elaboração da proposta, os professores de outras disciplinas como Artes, Biologia, Geografia e História participaram mais facilmente da sua implementação (Reis, 2016; Sampaio, 2017).

As propostas analisadas também apontam uma preocupação para discutir o contexto dos estudantes, seja em nível do cotidiano - temas presentes no dia-a-dia do estudante que costumam suscitar a interdisciplinaridade das disciplinas de Ciências para discutir curiosidades e se centram na dialética ensino e aprendizagem, como na proposta "O café nosso de cada dia" (Jesus, 2015); ou em nível de questões sociais - temas que exigem o diálogo entre as áreas das Ciências e humanidades, despertam o conhecimento científico suscitando o pensamento crítico dos estudantes sobre as questões sociais como em "Soberania alimentar" (Silva, 2019) e "Cacau de Jorge Amado" (Guimarães, 2017). 
No Cenário Integrador, deseja-se que os temas para a reconfiguração do currículo sejam de relevância social, que suscitem ações para transformação da realidade para que a construção da proposta planejada se desenvolva em uma perspectiva social. Considerase que as propostas analisadas apontam um movimento que caminha desde a promoção da tecnociência até o ativismo (Simonneaux, 2014).

Assim, as propostas que se restringem a valorizar o cotidiano e a futura atuação profissional dos estudantes e que consideram a sequência curricular dos conteúdos científicos como ponto de partida para o desenvolvimento da proposta de reconfiguração curricular tendem a apresentar baixos níveis de ativismo. Exemplo disso são as propostas apresentadas nos trabalhos de Amaral (2013), Fernandes (2014) e Pinto (2015), os quais tem como ponto de partida o conteúdo, demonstrando uma preocupação tecnocientífica, com a aprendizagem de conceitos e conhecimento científico (Simonneaux, 2014).

Em outra direção, as propostas que apresentam níveis de ativismo de intermediário a alto, se comprometem em desenvolver temas de relevância local de acordo com o contexto social em que a escola está inserida, com conteúdos científicos interdisciplinares e questões culturais. Algumas propostas que foram desenvolvidas têm essas características, bem como os trabalhos de Bomfim (2019) e Silva (2019), embora nesses trabalhos não sejam constatadas ações ativistas fora do âmbito escolar.

Pensando no desenvolvimento de propostas curriculares que promovam ações sociais, corroboramos com as ideias de Apple $(1989 ; 2011 ; 2017 \mathrm{a}$; 2017b) quando sugere que o educador deve ser um intelectual ativista. Portanto, entender as escolas e atuar nelas não é suficiente, é preciso utilizá-la para gerar ações significativas. Pois a cultura não é em si neutra, mas é um elemento que ajuda a manter a desigualdade fora da escola (Apple, 2006).

Sobre essa questão, Apple (2011; 2017 a; 2017 b) enfatiza que o pesquisador que pretende ser um "estudioso/ ativista crítico" deve extrapolar a teoria para realizar transformações no mundo real. Segundo o autor, "A teoria "manda de verdade", com poucas exceções, na realidade das instituições, em comunidades e em suas lutas. Para essas pessoas, a realidade se transformou em um "texto", um assunto para a desconstrução, mas com pouca ação concreta na solidariedade com oprimidos." (Apple, 2017 a, p. 70). Segundo Moreira (1989, p. 25), Apple apresenta "a necessidade de se pensar o currículo sempre em relação ao contexto social mais amplo", assim o uso de temas envolvendo raça, gênero e classe pode conferir altos níveis de ativismo, pois,

[...] é importante perceber que a educação é parte da sociedade. Ela não é algo que fica do lado de fora. De fato, ela é um conjunto primordial de instituições e um conjunto primordial de relações sociais e pessoais. Ela é simplesmente central para uma sociedade [...] onde as pessoas e o poder interagem (Apple, 2017, p. 39).

Nesse pensamento, orienta-se que a escolha do tema ocorra na dinâmica entre a Esfera de Elaboração e a Esfera de Implementação. Acredita-se que, quanto maior for a aproximação dos participantes da Comunidade Colaborativa com o espaço de ação possível, a emergência de um tema de alta relevância social para os sujeitos da esfera 
de implementação será mais facilmente evidenciada sendo possível planejar e realizar ações ativistas.

Para que os educadores estejam aptos a esta transformação é necessário entender profundamente as relações entre educação e as esferas ideológica, política e econômica e, como essas relações estão presentes na escola (Apple, 1989). Os educadores como sujeitos envolvidos no ambiente escolar devem ter como tarefa estudar as atividades diárias examinando-as por fatores políticos e econômicos. Isso, no entanto, não é o bastante para promover mudanças nas práticas diárias.

\section{Delineando temas de relevância social no contexto escolar}

Tendo em conta as ideias antes apresentadas, sugerem-se três etapas para possibilitar o processo de emergência do tema:

1. Conhecer o contexto escolar - Essa etapa consiste em conhecer o currículo da escola ou da disciplina, conhecer os projetos da escola, identificar professores, profissionais da educação e estudantes que estejam dispostos a participar da Comunidade Colaborativa e, para isso, algumas atividades interventivas podem ser realizadas na escola (Apple, 1999).

2. Particularizar a realidade escolar - A identificação do tema exige "particularizar a realidade" e a seleção de cultura que é preservada e distribuída na escola (Sacristán, 1998; Apple, 2006). Essa etapa consiste em investigar o tema a partir de conversas com estudantes, professores e funcionários da escola e, se possível, com moradores do entorno da escola. As informações podem ser coletadas por meio de questionários, entrevistas e rodas de conversa.

3. Extrapolar a realidade local - A particularidade da realidade escolar não diz tudo sobre os problemas que ela enfrenta, logo, é necessário identificar quais aspectos dos problemas globais mais amplos se manifestam ali. Para isso, é possível acompanhar a atividade escolar para identificar atitudes que apontem para o currículo oculto e discursos ideológicos e hegemônicos (Silva, 1995; Apple, 2006). Desse modo, Apple (2006) sugere três questões que ajudam a identificar esses discursos e situar a realidade da escola, as quais são:

(1) Como normas diárias da escola contribuem para que os alunos aprendam essas ideologias; (2) como as formas específicas do conhecimento curricular tanto no passado quanto hoje refletem essas configurações, e (3) como essas ideologias se refletem nas principais perspectivas que os próprios educadores empregam para ordenar, orientar e dar significado à sua própria atividade (p. 48).

Desvendar esses elementos pode auxiliar no desenvolvimento de um currículo mais justo. Isso pode ser realizado com anotações em diário sobre as observações na escola. É possível que desse processo surjam temas diversos, portanto, apontam-se, a seguir, três características desejáveis dessa escolha:

- Apresentar relevância social;

- Apresentar relevância científica; 
- Despertar a discussão de questões de dimensão local, nacional e global.

Após a escolha do tema, o documento da proposta de reconfiguração pode ser desenvolvido pela Comunidade Colaborativa, considerando etapas que possibilitem o ensino e a aprendizagem dos estudantes e que suscitem ações para solucionar os problemas relacionados ao tema discutido. Para isso, sugere-se pensar o conjunto de quatro momentos da aprendizagem, (Gehlen et al., 2012) a saber:

1. Problematização - A Problematização é o momento em que os problemas emergidos nas etapas de identificação do tema serão discutidos com os estudantes para que eles exponham seus entendimentos sobre aqueles encontrados na sua realidade. Para isso, o professor deve direcionar a discussão de modo que inicie abordando a dimensão do problema em nível local, partindo para o regional, nacional e mundial.

2. Estudo do problema - Esse momento consiste em que o problema seja estudado com os conceitos e conteúdos necessários, sejam eles específicos ou relacionados às áreas de humanidades ou Ciências da natureza, para que haja conhecimento inicial do conteúdo acadêmico.

3. Função do conhecimento - Nesse momento, o estudante deve conseguir explicar a origem e consequência do problema em sua realidade, o que significa a consistência no avanço da compreensão do conteúdo acadêmico para a resolução ou posicionamento do estudante quanto ao problema.

Esses três momentos contemplam um objetivo pedagógico a fim de que o estudante desenvolva o sistema cognitivo, mas não preveem ações para a solução prática do problema, por isso sugere-se um quarto momento.

4. Ação ativista - Esse momento consiste em que os professores e estudantes tomem medidas ativistas. Para exemplificar, ao pensar em um tema como "Lixo", é possível realizar ações como fazer abaixo-assinado de moradores do bairro ou enviar cartas solicitando a coleta de lixo, criar placas para evitar o descarte do lixo em lugares inadequados, realizar mutirão para a coleta. Desse modo, possibilita-se o ensino de Ciências comprometido com a sociedade, não só testemunhando a negatividade, mas, também, agindo para a mudança positiva (Apple, 2017).

Por fim, entende-se que desenvolver e implementar propostas de reconfiguração curricular em Cenários Integradores se relaciona com o fato de conectar indivíduos e escolas a comunidades. Concordando com as palavras de Gandin e Apple:

Precisamos nos engajar no trabalho duro de documentar esforços atuais em conectar nosso trabalho educacional com comunidades locais, especialmente aqueles membros dessas comunidades com menos poder, que são mais verdadeiramente democráticos do que as ideias de democracia "magra" visionado pela direita. Se não fizermos isso, definições neoliberais de democracia - baseada em individualismo possessivo e no qual cidadania reduzida a simples práticas de consumo - prevalecerão (Gandin \& Apple, 2017 p. 165). 
Nesse pensamento, as propostas de reconfiguração curricular podem ser instrumentos para o alcance de mudança dando poder a grupos subalternos e permitindo ouvir a voz de quem faz parte desses grupos. Extrapolando assim o foco conceitual, conteudista e tecnicista do ensino quando gerido numa perspectiva crítica e ativista.

\section{À guisa de conclusão}

Diante do objetivo de apresentar o processo de emergência e fundamentação da proposta de reconfiguração curricular Cenário Integrador, a análise documental realizada nesse artigo a partir do levantamento bibliográfico de TCCs e dissertações produzidos no âmbito da UESC por 10 anos, permitiu conhecer a dimensão quantitativa de produção acadêmica no âmbito desse grupo. Além disso, foi possível saber como, quais e porque diferentes concepções da reconfiguração curricular estão emergindo nesse contexto. Percebendo-se então um processo de pesquisa-ação não consciente, em que as anomalias, problemas, limitações e também possibilidades foram sistematizadas e estudadas, dando origem ao Cenário Integrador.

De acordo com o apresentado nesse artigo, consideramos que o Cenário Integrador é uma nova proposta de reconfiguração curricular que promove o ensino de Ciências por meio de temas de relevância social desenvolvido em colaboração por agentes que se disponibilizam a construir e implementar tal proposta a fim de reconfigurar o currículo.

Por meio da Esfera de Elaboração e Esfera de Implementação, essa proposta tem promovido a integração entre espaços escolares, acadêmicos e sociais. Ressalta-se que, devido à característica dinâmica das Esferas, uma vez elaboradas elas não devem ser reproduzidas e aplicadas uma segunda vez em uma mesma escola, turma ou em outros. Caso o tema ainda seja relevante para aquele grupo, é necessário que uma nova avaliação do tema seja realizada, para que sejam identificados os avanços, as peculiaridades e as diferenças dos problemas que expressem esse tema.

A estrutura do Cenário Integrador surgiu no processo de construção desta pesquisa e em uma série de reuniões do GPeCFEC. No entanto, embora tenha havido um avanço na estruturação dessa proposta, ela não está acabada, pois o período de desenvolvimento da pesquisa aqui apresentada é limitado e não suportaria alcançar o estudo de fatores como a interdisciplinaridade (intrínseca à discussão do tema), o desenvolvimento do professor em formação inicial e continuada na Comunidade Colaborativa, o estudo do desenvolvimento cognitivo do estudante possibilitado pelo ensino a partir do Cenário Integrador, entre outras questões que ainda devem ser respondidas ao longo dos anos pelo grupo de pesquisa.

A proposta de reconfiguração curricular Cenário Integrador apresentada nesse artigo, em si se configura como uma contribuição a comunidade científica, pois o seu desenvolvimento pode promover um ensino de Ciências mais comprometido com questões da justiça social, integrando conhecimentos científicos a temas de relevância social. Além disso, cabe ressaltar que a atuação do GPeCFEC por meio de propostas de reconfiguração curricular nessa região, tem possibilitado aos licenciandos uma formação 
diferenciada, que abre possibilidades de uma futura atuação mais humanizada. Ainda nessa perspectiva, os professores da Educação Básica também vêm sendo incentivados a participarem de ações de formação continuada, não apenas de modo informal como participantes do grupo de pesquisa, mas por meio do ingresso em Programas de PósGraduação.

Com isso, entende-se que a proposta Cenário Integrador pode ser uma fomentadora de uma formação de professores de Ciências que se alinhe às necessidades intrínsecas e extrínsecas de nossa sociedade, tendo potencial para promover melhorias na qualidade do ensino e ressignificando o sentido social e cultural da escola. Nesse sentido, é importante considerar que as escolas nas quais o GPeCFEC tem atuado, vêm fomentando a implementação da proposta de reconfiguração a pelo menos dez anos, o que mostra que a parceria estabelecida tem surtido efeito, ainda que isso demande dedicação e esforço de todos os integrantes. Além disso, muitos dos participantes desse grupo de pesquisa, que devido ao fluxo contínuo de permanência, se enveredam em outros contextos, outras realidades escolares de distintas cidades da região, acabam sendo multiplicadores desse tipo de ação ao atuarem valorizando o contexto da escola, e promovendo mudanças positivas nesses espaços. Por fim, destacamos que as pesquisas e ações promovidas nesse contexto tem tido um impacto regional para além do compromisso científico com as escolas, e estão abertas a novos horizontes de implementação.

\section{Agradecimentos}

Agradecemos às agências de fomento Fundação de Amparo à Pesquisa do Estado da Bahia (FAPESB) e a Coordenação de Aperfeiçoamento de Pessoal de Nível Superior (CAPES) e ao Conselho Nacional de Desenvolvimento Científico e Tecnológico (CNPq); aos integrantes do Grupo de Estudos sobre Abordagem Temática no Ensino de Ciências (GEATEC/UESC) pelas discussões deste texto; por fim, agradecemos e aos integrantes do Grupo de Pesquisa em Currículo e Formação de Professores em Ensino em Ciências (GPeCFEC).

\section{Referências}

Apple, M. W. (1989). Education and power. Routledge \& Kegan Paul.

Apple, M. W. (2000). Política cultural e educação. Cortez.

Apple, M. W. (2006). Ideologia e currículo. 3. ed. Artmed.

Apple, M. W. (2011). Global Crises, Social Justice, and Teacher Education. Journal of Teacher Education. 62(2), 222-234. https://dx.doi.org/10.1177/0022487110385428

Apple, M. W. (2017 b). A luta pela democracia na educação crítica. Revista e-Curriculum, 15(4), 894-926. https://dx.doi.org/10.23925/1809-3876.2017v15i4p894-926

Apple, M. W. (2017a) A educação pode mudar a sociedade? Vozes. 
Borba, F. S. (2004). Cenário. Borba, F. S. (org.). Dicionário UNESP do Português Contemporâneo. Ed. UNESP, São Paulo. 1470 p.

Campos, M. S. N., \& Reis, G. R. F. S. (2019). Os materiais narrativos e a reconfiguração dos currículos: Desafios e possibilidades. Currículo sem Fronteiras, 19(1), 396-417.

Delizoicov, D., Angotti, J. A., \& Pernambuco, M. M. (2011). Ensino de ciências: Fundamentos e métodos. $4^{\mathrm{a}} \mathrm{ed}$. Cortez.

Gehlen, S. T. , Maldaner, O. A., \& Delizoicov, D. (2012). Momentos Pedagógicos e as etapas da Situação de Estudo: Complementaridades e Contribuições para a Educação em Ciências. Ciências e Educação, 18(1), 1-22. https://doi.org/10.1590/S151673132012000100001

Guba, E. G. \& Lincoln, Y. S. (1981). Effective Evaluation. Ca. Jossey-Bass.

Kemmis, S. (2009). Action research as a practice-based practice. Educational Action Research, 17(3), 463-474. https://doi.org/10.1080/09650790903093284

Kemmis. S. \& Mctaggart. R. (Orgs.) (1988). The action Research planner. 3 ed. Geelong, Deakin University Press.

Kuhn, T. (1996). A estrutura das revoluções científicas. 4 ed. Perspectiva.

Ludke, M., \& André, M. E. D. A. (1986). Pesquisa em educação: Abordagens qualitativas. EPU.

Maia, R. (1995). Configuração. In R. Maia. Magno Dicionário Brasileiro da Língua Portuguesa. Edipar.

Maldaner, O. A. (2007). Situações de estudo no ensino médio: Nova compreensão de educação básica. In R. Nardi (Org.), A pesquisa em ensino de ciências no Brasil: Alguns recortes (pp. 239-254). Escrituras.

Maldaner, O. A., \& Zanon, L. B. (2006). Situação de Estudo: Uma organização do ensino que extrapola a formação disciplinar em Ciências. In R. Moraes, R. Mancuso (Orgs.), Educação em Ciências: Produção de currículos e formação de professores (pp. 43-175). Ed. UNIJUÍ.

Massena. E. P., \& Brito, L. D. (2015). Caminhos e descaminhos da Situação de Estudo (Situação de Estudo): A experiência vivenciada por um grupo de formadores de professores. In Masena, E. P. (Org). (2015). Situação de Estudo: Processo de significação pela pesquisa em grupos interinstitucionais. Ed. Unijuí.

Mesquita, S. S. de A. (2019). A centralidade do papel dos professores do ensino médio na reconfiguração do currículo e da profissão. Revista e-Curriculum, 17(1), 230-255. http://dx.doi.org/10.23925/1809-3876.2019v17i1p230-255

Moraes, R., \& Galiazzi, M. do C. (2013). Análise Textual Discursiva. 2 ed. Ed. UNIJUÍ. 
Moreira, A. F. B. (1989). A contribuição de Michael Apple para o desenvolvimento. Fórum educacional, 13(4),17-30.

Pansera-de-Araújo, M. C., Auth, M. A. E., \& Maldaner, O. A. (2007). Situações de Estudo como forma de inovação curricular em Ciências Naturais. In M. C. Galiazzi, M. A Auth, R. Moraes, \& R. Mancuso (Orgs.), Construção curricular em rede em educação na Educação em Ciências: Uma aposta de pesquisa na sala de aula (pp. 161-176). Ed. UNIJUÍ.

Pedretti, E., \& Nazir. J. (2011). Currents in STS Education: Mapping a Complex Field, 40 Years On. Science Education.

Ratcliffe M., \& Grace, M. (2003). Science education for citizenship: Teaching socioscientific issues. Maidenhead: Open University Press.

Sacristán, J. G. (1998). O currículo: Os conteúdos do ensino ou uma análise prática?. In J. G. Sacristán, \& A. I. Pérez-Gomez (Orgs.), Compreender e transformar o ensino (pp. 119-148) 4. ed. Tradução de: Ernani F. da Fonseca Rosa. Artmed.

Silva, T. T. (1995). Currículo e identidade social: territórios contestados. In T. T. Silva (Org.), Alienígenas na sala de aula: Uma introdução aos estudos culturais em educação (pp. 190-207). 9 ed. Vozes.

Simonneaux, L. (2014). Questions Socialement Vives and Socio-scientific Issues: New Trends of Research to Meet the Training Needs of Postmodern Society. In C. Bruguière, A. Tiberghien, \& P. Clément (Éd.), Topics and Trends in Current Science Education: $9^{\text {th }}$ ESERA Conference Selected Contributions (pp. 37-54) (Contributions from Science Education Research Book 1). Dordrecht, The Netherlands: Spinger Verlag.

Tripp, D. (2005). Pesquisa-ação: Uma introdução metodológica. Educ. Pesqui., 31(3), 443-466.

Vieira, L. B. G., Fernandes, G. W. R., Massena, E. P., \& Maldaner, O. A. (2018). Situação de Estudo: $\mathrm{O}$ que vem sendo publicado em eventos e periódicos da área de ensino de ciências? Revista Ensaio. Belo Horizonte, 20, e2914. https://doi.org/10.1590/198321172018200101

Winter, R. (2005). Some Principles and Procedures for the Conduct of Action Research. In O. Zubert-Skerrtitt, (Org.). New directions in action research (pp. 9-22). Taylor \& Francis e-Library.

Ximenes, S. (2000). Minidicionário da Língua Portuguesa. ed. 2. Ed. Ediouro.

Zubert-Skerrtitt, O. (2005). Emancipatory Action Research For Organisational Change and Management Development. In O. Zubert-Skerrtitt (Org.) New directions in action research (pp. 68-87). Taylor \& Francis e-Library. 


\section{Referências de TCC e Dissertações utilizadas como corpus de dados}

Almeida, C. L. S. (2017). Situação de Estudo na formação de professores em escolas do campo de Coaraci-BA. (Dissertação). Universidade Estadual de Santa Cruz-UESC, Ilhéus, Brasil.

Alves. W. F. S. (2018). Saberes Docentes na Formação Inicial de Professores de Ciências: (Re)pensando práticas educativas por meio da Situação de Estudo. (Dissertação). Universidade Estadual de Santa Cruz-UESC, Ilhéus, Brasil.

Amaral, G. (2013). Situação de Estudo: Uma nova abordagem curricular no curso técnico em Biotecnologia. (Monografia). Universidade Estadual de Santa Cruz-UESC, Ilhéus, Brasil.

Bomfim, R. C. (2016) Automedicação como tema de Situação de Estudo para o Ensino de Química. (Monografia). Universidade Estadual de Santa Cruz-UESC, Ilhéus, Brasil.

Bomfim, R. C. (2019). (Dissertação). O trabalho colaborativo na interface universidadeescola: (re)pensando o currículo por meio da Situação de Estudo. Universidade Estadual de Santa Cruz-UESC, Ilhéus, Brasil.

Fernandes. G. F. (2014). Contribuições da situação de estudo à formação inicial de professores de química da Universidade Estadual de Santa Cruz. (Monografia). Universidade Estadual de Santa Cruz-UESC, Ilhéus, Brasil.

Guimarães, T. S. (2017). O uso da literatura de Jorge Amado no Ensino de ciências: Uma possibilidade a partir de uma Situação de Estudo. (Monografia). Universidade Estadual de Santa Cruz-UESC, Ilhéus, Brasil.

Jesus, D. (2016). O café nosso de cada dia: Investigação da influência de uma situação de estudo no processo de ensino aprendizagem de ciências da natureza no ensino médio. (Dissertação). Universidade Estadual de Santa Cruz-UESC, Ilhéus, Brasil.

Pereira, D. B. (2017). Alimento e gastrite: Possíveis contribuições da Situação de Estudo para o PROEJA. (Monografia). Universidade Estadual de Santa Cruz-UESC, Ilhéus, Brasil.

Pimenta, S. S. (2016). Conhecendo a química dos cabelos cacheados: uma situação de estudo no curso técnico. (Monografia). Universidade Estadual de Santa Cruz-UESC, Ilhéus, Brasil.

Pinto, J. G. R. (2015). Situação de Estudo: Automedicação, um mal necessário? Uma abordagem curricular em um curso Técnico. (Monografia). Universidade Estadual de Santa Cruz-UESC, Ilhéus, Brasil.

Reis, C. M. R. (2016). Educação de Jovens e Adultos: A Situação de Estudo como possibilidade de repensar o currículo. (Monografia). Universidade Estadual de Santa Cruz-UESC, Ilhéus, Brasil. 
Resende, R. C. S. (2015). Desenvolvimento de Situação de Estudo como facilitadora do processo de ensino e aprendizagem de ciências da natureza no $9^{\circ}$ ano do ensino fundamental. (Dissertação). UESC, Ilhéus, Brasil.

Sampaio, T. S. (2017). Educação de Jovens e Adultos: Atividade de formação continuada baseado nos pressupostos da Situação de Estudo. (Monografia). Universidade Estadual de Santa Cruz-UESC, Ilhéus, Brasil.

Santos, C. E. J. (2016). Possíveis contribuições da proposta curricular Situação de Estudo no currículo da educação de jovens e adultos. (Monografia). Universidade Estadual de Santa Cruz-UESC, Ilhéus, Brasil.

Silva, F A. N. (2019). Situação de Estudo na formação de professores do MST: Diálogos com Henri A. Giroux. (Dissertação). Universidade Estadual de Santa Cruz-UESC, Ilhéus, Brasil.

Silva, U. K. F. (2017). Rio Almada: Uma Situação de Estudo como proposta para o ensino de Química.pp 51. Graduação em Licenciatura em Química. Universidade Estadual de Santa Cruz. Ilhéus, Bahia.

Sousa, P. S. (2018). Desenvolvimento profissional docente no contexto da reconfiguração curricular pela Situação de Estudo. (Dissertação). Universidade Estadual de Santa CruzUESC, Ilhéus, Brasil.

Vieira, L. B. G. (2017). Situação de Estudo: Compreensões dos formadores de professores do ensino de Ciências. (Dissertação). Universidade Estadual de Santa Cruz-UESC, Ilhéus, Brasil.

\section{Sara Souza Pimenta}

https://orcid.org/0000-0002-9588-7243

Universidade Estadual de Santa Cruz Programa de Pós-Graduação em Educação em Ciências Departamento de Ciências Exatas e Tecnologia Ilhéus, Bahia, Brasil pimenta.sara@outlook.com Thiago Santos Guimarães

https://orcid.org/0000-0003-0709-5439 Universidade Estadual de Santa Cruz Programa de Pós Graduação em Educação em Ciências e Matemática Departamento de Ciências Exatas e Tecnologia Ilhéus, Bahia, Brasil thiago.s.guimaraes41@gmail.com 
Nataélia Alves da Silva

https://orcid.org/0000-0002-2167-1255

Universidade Estadual de Santa Cruz Programa de Pós-Graduação em Educação em Ciências Departamento de Ciências Exatas e Tecnologia Ilhéus, Bahia, Brasil natyalves_@hotmail.com

\section{Andrei Steveen Moreno Rodríguez}

${ }^{-1}$ https://orcid.org/0000-0002-3743-4633

Universidade Estadual de Santa Cruz Programa de Pós Graduação em Educação em Ciências e Matemática Departamento de Ciências Exatas e Tecnologia Ilhéus, Bahia, Brasil wontola48@gmail.com

\section{Elisa Prestes Massena}

${ }^{\circ}$ https://orcid.org/0000-0002-7670-0201

Universidade Estadual de Santa Cruz

Programa de Pós Graduação em Educação em Ciências e Matemática Departamento de Ciências Exatas e Tecnologia Ilhéus, Bahia, Brasil elisapmassena@gmail.com

Submetido em 05 de abril de 2020 Aceito em 08 de setembro de 2020 Publicado em 27 de outubro de 2020 